Pacific Northwest

National Laboratory

Operated by Battelle for the

U.S. Department of Energy

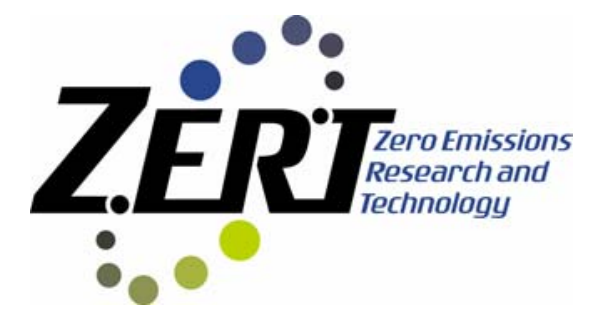

PNNL-16137
R. T. Dahowski

Pacific Northwest National Laboratory

S. Bachu

Alberta Geological Survey

Alberta Energy and Utilities Board

March 2007

Prepared for the U.S. Department of Energy under Contract DE-AC05-76RL01830 


\title{
DISCLAIMER
}

This report was prepared as an account of work sponsored by an agency of the United States Government. Neither the United States Government nor any agency thereof, nor Battelle Memorial Institute, nor any of their employees, makes any warranty, express or implied, or assumes any legal liability or responsibility for the accuracy, completeness, or usefulness of any information, apparatus, product, or process disclosed, or represents that its use would not infringe privately owned rights. Reference herein to any specific commercial product, process, or service by trade name, trademark, manufacturer, or otherwise does not necessarily constitute or imply its endorsement, recommendation, or favoring by the United States Government or any agency thereof, or Battelle Memorial Institute. The views and opinions of authors expressed herein do not necessarily state or reflect those of the United States Government or any agency thereof.

\author{
PACIFIC NORTHWEST NATIONAL LABORATORY \\ operated by \\ BATTELLE \\ for the \\ UNITED STATES DEPARTMENT OF ENERGY \\ under Contract DE-ACO5-76RL01830
}

Printed in the United States of America
Available to DOE and DOE contractors from the
Office of Scientific and Technical Information,
P.O. Box 62, Oak Ridge, TN 37831-0062;
ph: (865) 576-8401
fax: (865) 5765728
email: reports@adonis.osti.gov

\footnotetext{
Available to the public from the National Technical Information Service, U.S. Department of Commerce, 5285 Port Royal Rd., Springfield, VA 22161 ph: (800) 553-6847 fax: (703) 605-6900

email: orders@nits.fedworld.gov online ordering: http://www.ntis.gov/ordering.htm
} 


\section{Assessing the Effect of Timing of Availability for Carbon Dioxide Storage in the Largest Oil and Gas Pools in the Alberta Basin: Description of Data and Methodology}

R. T. Dahowski

Pacific Northwest National Laboratory

S. Bachu

Alberta Geological Survey

Alberta Energy and Utilities Board

March 2007

Prepared for the U.S. Department of Energy

under Contract DE-AC05-76RL01830

Pacific Northwest National Laboratory

Richland, Washington 99352 


\section{Executive Summary}

Carbon dioxide $\left(\mathrm{CO}_{2}\right)$ capture from large stationary sources and storage in geological media is a technologically feasible option for reducing anthropogenic emissions of $\mathrm{CO}_{2}$ to the atmosphere in response to climate change. Carbon dioxide can be sequestered underground in various types of geologic formations, including oil and gas reservoirs, deep saline formations, uneconomic coal beds, and salt caverns. The Alberta Basin provides a very large capacity for $\mathrm{CO}_{2}$ storage in oil and gas reservoirs, along with significant capacity in deep saline formations and possibly in unmineable coal beds.

Regional assessments of potential geological $\mathrm{CO}_{2}$ storage capacity have thus far focused primarily on estimating the total volumetric capacity that might be available within each type of reservoir. While deep saline formations are effectively capable of accepting $\mathrm{CO}_{2}$ immediately, the storage potential of other classes of candidate storage reservoirs - particularly oil and gas fields - is not fully available at present. Capacity estimates to date have largely overlooked rates of depletion in these types of storage reservoirs and typically report the total estimated storage capacity that will be available upon depletion. However, $\mathrm{CO}_{2}$ storage will not (and cannot economically) begin until the recoverable oil and gas have been produced via traditional means.

This report describes a reevaluation of the $\mathrm{CO}_{2}$ storage capacity and an assessment of the timing of availability of the oil and gas pools with very large storage capacity within the Alberta Basin that represent likely targets for early implementation of $\mathrm{CO}_{2}$ storage in the region. Over 36,000 individual (i.e., non-commingled) oil and gas pools were examined and evaluated for storage capacity. The resulting cumulative capacity for the basin is approximately $10 \mathrm{GtCO}_{2}$, with gas pools providing over $90 \%$ of that total. Additional criteria were applied that reduced the set to 227 pools with individual $\mathrm{CO}_{2}$ storage capacity greater than $5 \mathrm{MtCO}_{2}$, and a combined total estimated $4.7 \mathrm{GtCO}_{2}$ storage capacity for the region. For each pool, the life expectancy was estimated based on a combination of production decline analysis constrained by the remaining recoverable reserves and an assessment of economic viability, yielding an estimated depletion date, and the year that the pool will likely be available for $\mathrm{CO}_{2}$ storage.

This approach facilitates the development of a projected timeline for $\mathrm{CO}_{2}$ storage availability across the basin and enables a more realistic examination of potential oil and gas field $\mathrm{CO}_{2}$ storage utilization by the region's large $\mathrm{CO}_{2}$ point sources. The modeling framework and assumptions used to assess the impact of the timing of $\mathrm{CO}_{2}$ storage resource availability on the region's deployment of carbon dioxide capture and storage (CCS) technologies is also described. Incorporating the timing of availability into existing methodologies, a progression from current "static" $\mathrm{CO}_{2}$ storage supply curves to more realistic timedependent, or "dynamic" curves, is advanced. The resulting curves more clearly illustrate the likely mix of available storage resources across the basin and better represent the potential opportunity for the large $\mathrm{CO}_{2}$ point sources to access the region's many different classes of $\mathrm{CO}_{2}$ storage reservoirs over time.

The focus of this report is to describe the data and methodology for examining the $\mathrm{CO}_{2}$ storage resource of a major hydrocarbon province incorporating estimated depletion dates for its oil and gas fields with the largest potential $\mathrm{CO}_{2}$ storage capacities. The Alberta Basin of western Canada was selected for this initial examination as a representative mature basin, and the development of capacity and depletion-date estimates for the 227 largest oil and gas pools (with a total storage capacity of $4.7 \mathrm{GtCO}_{2}$ ) is described, along with the impact on source-reservoir pairing and resulting $\mathrm{CO}_{2}$ transport and storage economics. The analysis indicates that the timing of storage resource availability has a significant impact on the mix 
of storage reservoirs selected for use at a given time and further confirms the value that all available reservoir types will likely offer in a carbon-constrained world, providing important insights regarding $\mathrm{CO}_{2}$ storage implementation to this and other major oil and gas basins throughout North America and the rest of the world.

For CCS technologies to deploy successfully and offer a meaningful contribution to climate change mitigation, $\mathrm{CO}_{2}$ storage reservoirs must be available not only where needed (preferably co-located with or near large concentrations of $\mathrm{CO}_{2}$ sources or emissions centers) but also when needed. The timing of $\mathrm{CO}_{2}$ storage resource availability is therefore an important factor to consider when assessing the real opportunities for CCS deployment in any given region. 


\section{Acronyms}

$\begin{array}{ll}\text { CCS } & \text { carbon dioxide capture and storage } \\ \mathrm{CO}_{2} & \text { carbon dioxide } \\ \text { ECBM } & \text { enhanced coal-bed methane (recovery) } \\ \text { EIA } & \text { Energy Information Administration } \\ \text { EOR } & \text { enhanced oil recovery } \\ \text { GHG } & \text { greenhouse gas } \\ \text { GIS } & \text { Geographic Information System } \\ \text { GOR } & \text { gas-oil ratio } \\ \text { HCPV } & \text { hydrocarbon pore volume } \\ \text { IEA GHG } & \text { IEA Greenhouse Gas R\&D Programme } \\ \text { IPCC } & \text { Intergovernmental Panel on Climate Change } \\ \text { MMP } & \text { minimum miscibility pressure } \\ \text { OGIP } & \text { original gas in place } \\ \text { OOIP } & \text { original oil in place } \\ \text { WCSB } & \text { Western Canada Sedimentary Basin } \\ \text { WGR } & \text { water-gas ratio } \\ \text { WOR } & \text { water-oil ratio }\end{array}$





\section{Contents}

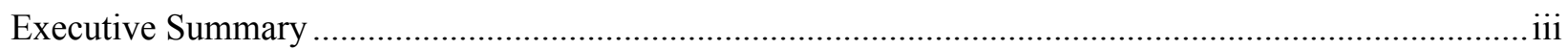

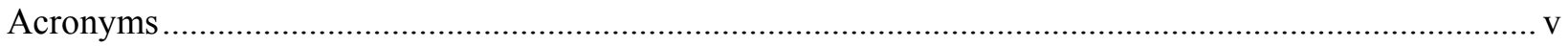

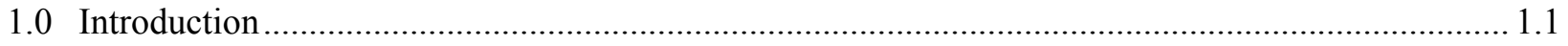

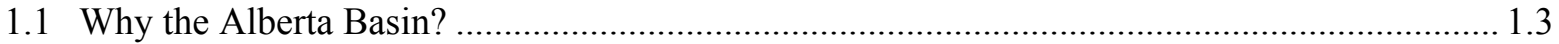

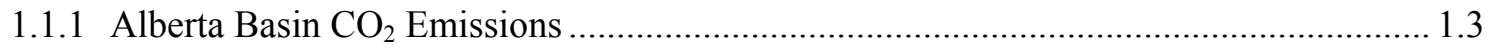

1.1.2 Candidate $\mathrm{CO}_{2}$ Storage Reservoirs of the Alberta Basin .......................................... 1.3

2.0 Methodology for Estimating $\mathrm{CO}_{2}$ Storage Capacity in Oil and Gas Reservoirs and their Timing

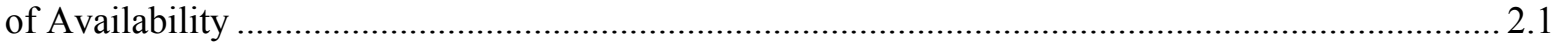

2.1 Oil and Gas Reservoir Storage Capacity Calculation Methodology …................................... 2.1

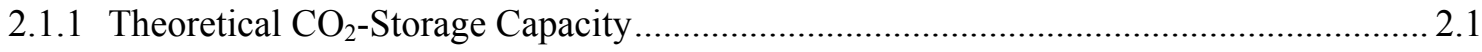

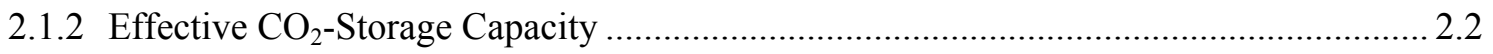

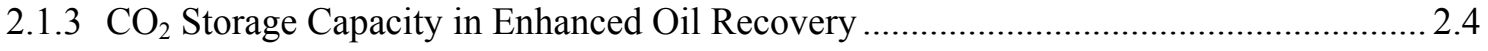

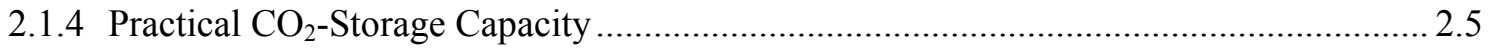

2.2 Methodology for Estimating Oil and Gas Reservoir Timing of Availability ........................... 2.6

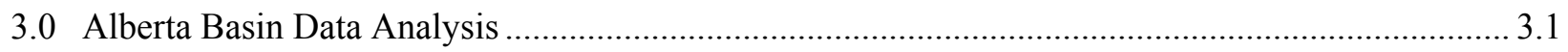

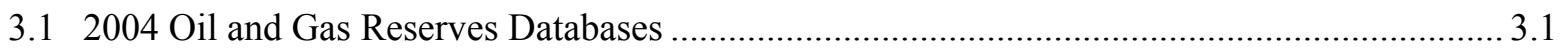

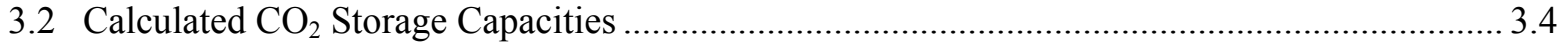

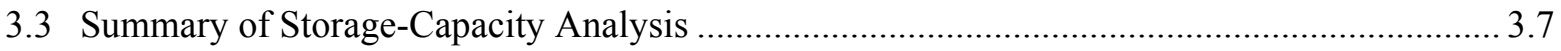

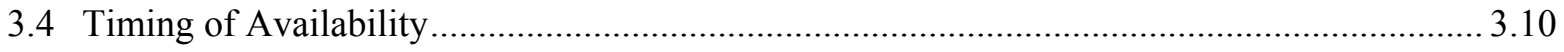

4.0 Source-Reservoir Matching and Cost-Curve Methodology ...................................................... 4.1

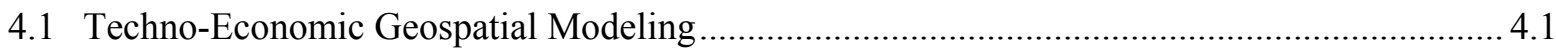

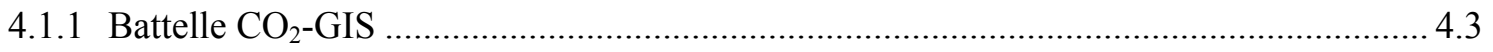

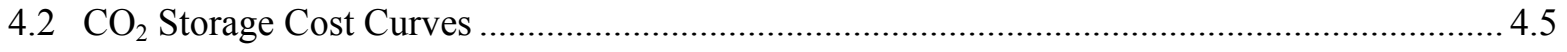

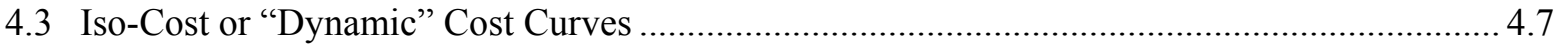

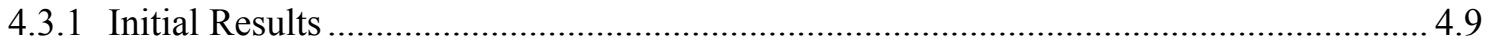

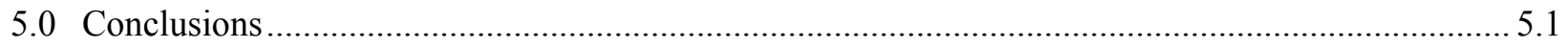

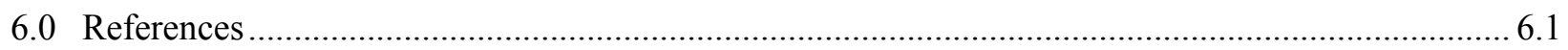




\section{Figures}

1.1. Large, Stationary $\mathrm{CO}_{2}$ Sources in the Western Canadian Sedimentary Basin............................... 1.2

1.2. Large $\mathrm{CO}_{2}$ Sources of the Alberta Basin and Surrounding Area ............................................... 1.4

2.1. Production Decline Analysis for the Blueridge Jurassic B Pool in Alberta..................................2.8

2.2. Production Decline Analysis for the Taber North Glauconitic A Oil Pools in Alberta ...................2.9

3.1. Histogram of the Oil and Gas Pools in Alberta with Individual Storage Capacity Greater than

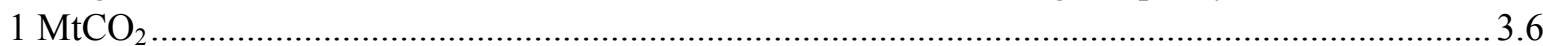

3.2. Histogram of the Oil and Gas Pools in Northeastern British Columbia with Individual Storage

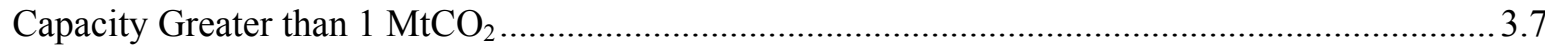

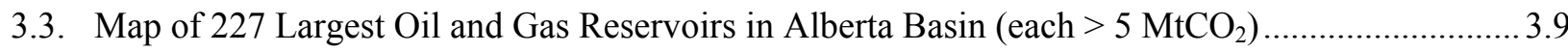

3.4. Histogram of Timing of Availability for the 227 Pools in the Alberta Basin with very Large $\mathrm{CO}_{2}$-Storage Capacity ( $>5 \mathrm{MtCO}_{2}$ each): by $\mathrm{CO}_{2}$ Storage Capacity that Will Become Available Annually, and Cumulative $\mathrm{CO}_{2}$-Storage Capacity over Time.

4.1. Location of the Large $\mathrm{CO}_{2}$ Point Sources ( $>100 \mathrm{ktCO}_{2} /$ year) and the 227 Oil and Gas Pools in the Alberta Basin with the Largest $\mathrm{CO}_{2}$ Storage Capacity ( $>5 \mathrm{MtCO}_{2}$ each), Plus the Location of Deep Saline Formations and Unmineable Coal Seams (south-southwest Alberta)

4.2. Alberta Basin $\mathrm{CO}_{2}$ Transport and Storage "Static" Cost Curve for First 10 Years-Ignoring Timing of Storage Resource Availability .....

4.3. Alberta Basin $\mathrm{CO}_{2}$ Transport and Storage "Static" Cost Curve for First 10 Years - Considering Timing of Storage Resource Availability .....

4.4. Timing of $\mathrm{CO}_{2}$ Storage Capacity Availability Grouped by Decade for the Largest 227 Oil and Gas Reservoirs in the Alberta Basin, Western Canada $\left(\mathrm{MtCO}_{2}\right.$ of new capacity within each time period)

4.5. Dynamic (iso-cost) $\mathrm{CO}_{2}$ Transport and Storage Cost Curves for the Alberta Basin, Canada, for each Decade Through 2070 


\section{Tables}

2.1. Criteria for Establishing the Strength and Effect of Underlying Aquifers on the $\mathrm{CO}_{2}$ Storage Capacity in Depleted Oil and Gas Reservoirs in the Western Canada Sedimentary Basin and the Corresponding Storage Capacity Reduction Coefficient.

3.1. Type of Oil Production and Corresponding Number of Oil Reservoirs in Alberta's 2004

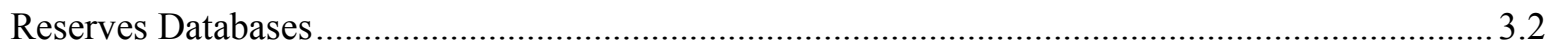

3.2. Type and Number of Oil Reservoirs in Northeastern British Columbia as per B.C. 2004 Reserves Database, Showing also the Availability of Critical Data ............................................. 3.3

3.3. Range of Characteristics of Oil and Gas Pools in the Alberta Basin that Have the Whole Suite of Data Needed for $\mathrm{CO}_{2}$-Storage Capacity Calculations ............................................................ 3.3

3.4. Characteristics of $\mathrm{CO}_{2}$ Storage Capacity in Oil and Gas Pools in Alberta ...................................... 3.4

3.5. Summary of Alberta Basin Oil and Gas Pools by Type, Quantity, and Estimated $\mathrm{CO}_{2}$ Storage Capacity $\left(\mathrm{MtCO}_{2}\right)$ 


\subsection{Introduction}

The engineered separation of carbon dioxide $\left(\mathrm{CO}_{2}\right)$ from the flue gases and process streams of large power plants and industrial facilities and its safe emplacement in deep geologic formations is being examined as one means of helping to mitigate climate change. This process, known as carbon dioxide capture and storage, or CCS, is designed to keep $\mathrm{CO}_{2}$, the most abundant greenhouse gas, out of the atmosphere. Once captured, the $\mathrm{CO}_{2}$ is compressed and transported to a suitable injection site where it is injected deep into underground formations that provide secure, long-term storage of the $\mathrm{CO}_{2}$. The following types of geological media are being considered for $\mathrm{CO}_{2}$ storage (IPCC 2005):

- depleted oil and gas reservoirs

- deep saline formations, saturated with brackish water or brine

- uneconomic coal seams, that are considered unmineable

- man-made underground cavities (i.e., salt caverns).

Ongoing research indicates that there is sufficient capacity in geologic formations to help society address the issue of climate change by deploying CCS within a portfolio of advanced, low-greenhouse gas energy technologies (Dooley et al. 2006). A recent technical review by the Intergovernmental Panel on Climate Change (IPCC 2005) reports that global geologic $\mathrm{CO}_{2}$ storage capacity is large, although unevenly distributed, and offers retention times of centuries to millions of years.

Assessments of potential geological $\mathrm{CO}_{2}$ storage capacity to date have largely focused on estimating the total volumetric capacity that might be available when each reservoir is ready for injection. While deep saline formations are effectively able to accept $\mathrm{CO}_{2}$ "today," the storage potential of other classes of candidate storage reservoirs, primarily oil and gas fields, is not fully available at present, with capacity coming online only as each field reaches the end of its economic production period. Capacity estimates so far have largely overlooked the fact that many of these reservoirs are still producing and that $\mathrm{CO}_{2}$ storage will not (and cannot economically) begin until the recoverable oil and gas have been produced. Capacity estimates have therefore reported total potential storage capacity at depletion, without regard to remaining recoverable reserves or estimating when depletion may occur. Because oil and gas pools within a given region are usually in various stages of production at any given time, it is critical to understand when each will be ready for $\mathrm{CO}_{2}$ injection, how this may impact the overall storage capacity of the region, and the variability in the costs associated with accessing a required volume of storage capacity over time.

Therefore, the purpose of this report is to describe a methodology for evaluating the timing of availability of individual fields within a major oil and gas province, along with estimating their $\mathrm{CO}_{2}$ storage capacity. An approach is outlined that facilitates the development of a projected timeline for $\mathrm{CO}_{2}$ storage availability across the basin and enables a more realistic examination of oil- and gas-field $\mathrm{CO}_{2}$ storage utilization by the area's large $\mathrm{CO}_{2}$ point sources. The Alberta Basin of western Canada was selected for this initial examination, and it is believed that what is learned here can be applied to other major oil- and gas-producing regions throughout North America and the rest of the world.

The Alberta Basin—which underlies northeastern British Columbia and most of Alberta —and the Canadian part of the Williston Basin in Saskatchewan and Manitoba are together known as the Western Canada Sedimentary Basin (WCSB) (Figure 1.1). The Alberta Basin has significant $\mathrm{CO}_{2}$ storage capacity 
in deep saline formations, depleting oil and gas fields, and possibly in coal beds if the technology proves successful. The basin also meets all the general suitability criteria for $\mathrm{CO}_{2}$ geological storage, has significant potential for $\mathrm{CO}_{2}$ storage, and, serendipitously, is home to many major stationary $\mathrm{CO}_{2}$ sources - such as thermal power plants, refineries, and cement, oil sands, gas, and petrochemical plants (Hitchon et al. 1999; Bachu and Stewart 2002; Bachu 2003).

Worldwide, the largest $\mathrm{CO}_{2}$-storage capacity is likely in deep saline formations, while the smallest is in coal beds (IPCC 2005), and this is probably true of the Alberta Basin as well. Though deep saline formations provide the largest target for $\mathrm{CO}_{2}$ storage, it is recognized that, generally, $\mathrm{CO}_{2}$ storage in geological media will often occur first in oil and gas reservoirs for the following reasons (IPCC 2005):

- their geology and trapping characteristics are better known as a result of exploration for and production of hydrocarbons

- there is already infrastructure in place (pipelines and wells)

- in the case of oil reservoirs that are suitable for $\mathrm{CO}_{2}$-flood enhanced oil recovery (EOR), additional oil production will lower the cost of $\mathrm{CO}_{2}$ storage, in some cases even realizing a profit, and will increase the stability and security of energy supplies.

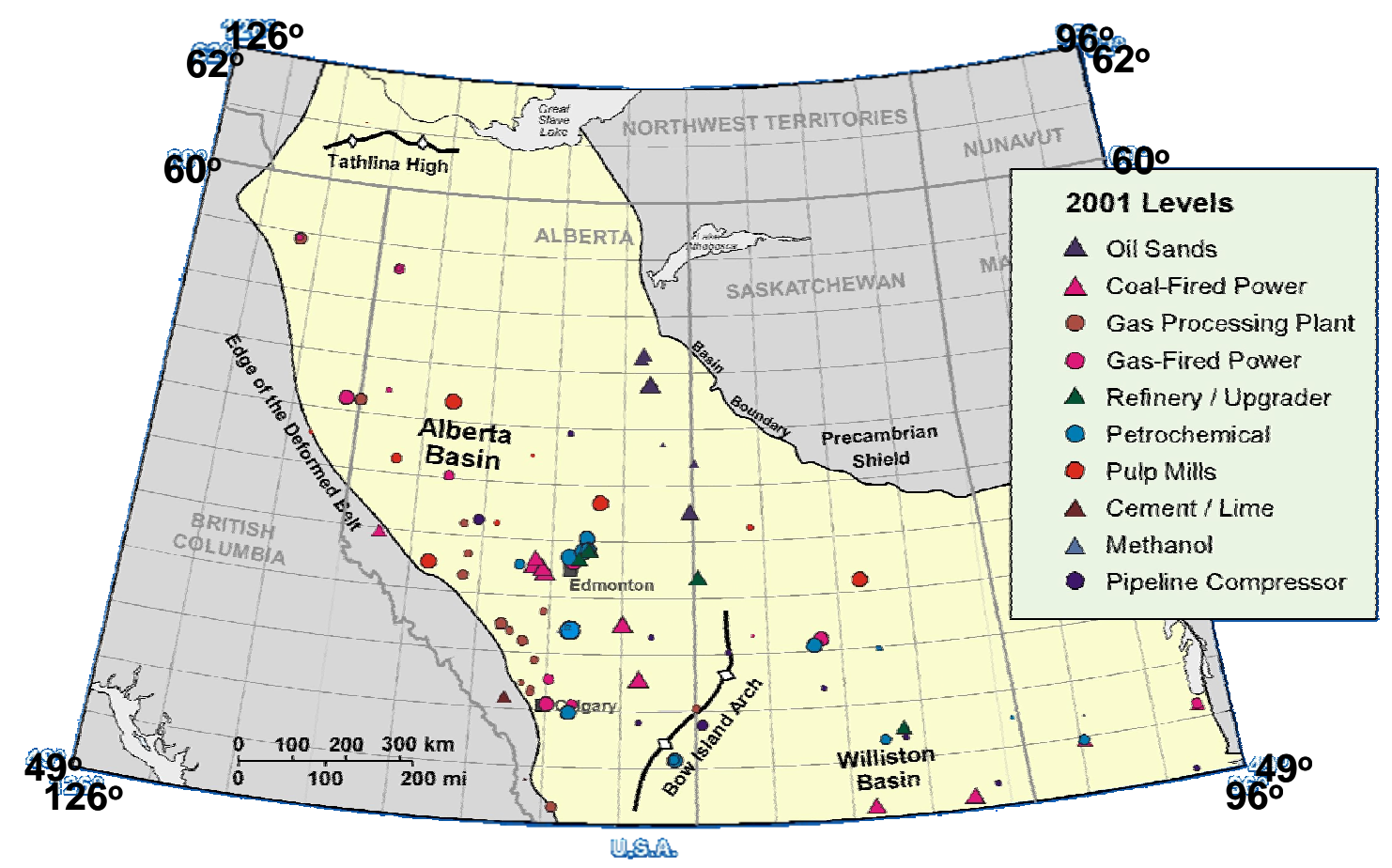

Figure 1.1. Large, Stationary $\mathrm{CO}_{2}$ Sources in the Western Canadian Sedimentary Basin

However, given that the individual $\mathrm{CO}_{2}$ storage capacity of most oil and gas pools is quite small (and in many cases too small to be considered an economic storage target for most large anthropogenic $\mathrm{CO}_{2}$ sources) and that not all pools may be available when needed, it is the goal of this analysis to assess the value that oil and gas pools may offer to this region in deploying CCS. In addition to the data and methodologies presented for estimating storage capacity and timing of availability, a methodology for 
assessing the impact of these factors on the cost and selection of target storage reservoirs by the region's large $\mathrm{CO}_{2}$ sources is examined. Preliminary results showing the relative utilization of the various types of storage reservoirs are presented and discussed.

\subsection{Why the Alberta Basin?}

The Alberta Basin of Western Canada was selected for application of this methodology and analysis for a number of key reasons. First, it is a mature oil and gas basin that is now in production decline. The basin has been a significant source of oil and natural gas since development began in the 1940s, and these maturing oil and gas reservoirs are now being considered for storing $\mathrm{CO}_{2}$ in an effort to address climate change. As in other oil and gas producing regions, depleted hydrocarbon reservoirs can provide significant $\mathrm{CO}_{2}$ storage capacity and, where readily accessible to the many large stationary $\mathrm{CO}_{2}$ sources that are located there, can provide attractive storage targets. Finally, and perhaps most important to the viability of the analysis, the necessary data on oil and gas pool production and reserves for the region were readily available and accessible from provincial regulatory agencies in Alberta and British Columbia. In many other locations, it would be significantly more difficult to access the level and detail of data required to perform this type of broad regional analysis. However, it is hoped that the methodologies and lessons developed here for the Alberta Basin can be transferred and applied in other major oil and gas provinces.

\subsubsection{Alberta Basin $\mathrm{CO}_{2}$ Emissions}

As of 2001, there were 81 large stationary sources of anthropogenic $\mathrm{CO}_{2}$ located within the Alberta Basin. These large $\mathrm{CO}_{2}$ point sources each emit at least 100,000 tons of $\mathrm{CO}_{2}$ per year, and consist of a mix of coal- and other fossil-fueled electric power plants, oil sands plants, refineries and upgrading facilities, petrochemical plants, and other sources, as shown in Figure 1.1. The bulk of the emissions originate in Alberta. The largest single source emits close to 16 million tons of $\mathrm{CO}_{2}\left(\mathrm{MtCO}_{2}\right)$ each year, and in all, these 81 large stationary sources emit $120 \mathrm{MtCO}_{2} / \mathrm{yr}$. The 10 largest sources are together responsible for over $50 \%$ of the total cumulative emissions, as illustrated in Figure 1.2.

\subsubsection{Candidate $\mathrm{CO}_{2}$ Storage Reservoirs of the Alberta Basin}

Depleted oil and gas fields, given their demonstrated capability to hold hydrocarbons for thousands of years, have been identified as two types of potential $\mathrm{CO}_{2}$ storage reservoirs. As stated above, there are depleted and depleting oil and gas fields throughout large areas of the basin. Additionally, other classes of potentially attractive $\mathrm{CO}_{2}$ storage reservoirs, such as deep saline formations and deep coal seams, also exist within the basin. In fact, several deep saline sedimentary formations with a very large potential $\mathrm{CO}_{2}$ storage capacity underlie much of the basin. Value-added $\mathrm{CO}_{2}$ storage could be found within some of the oil and coal targets where injection of $\mathrm{CO}_{2}$ may result in the recovery of additional oil and coalbed methane. Total $\mathrm{CO}_{2}$ storage capacity within the basin is estimated in the hundreds of billions of tons of carbon dioxide $\left(\mathrm{GtCO}_{2}\right)$, with the overwhelming majority of this capacity believed to be in deep saline formations. 


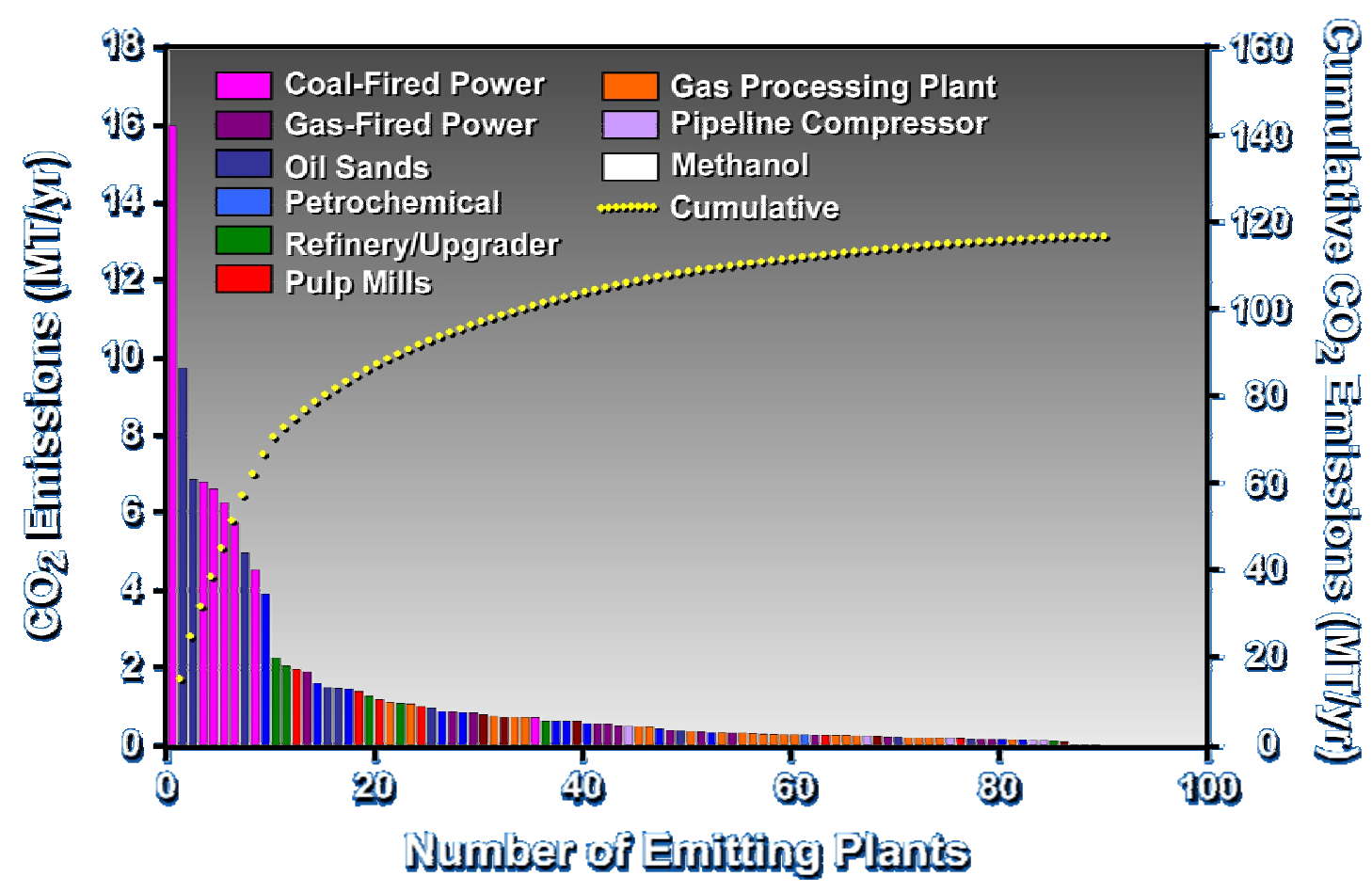

Figure 1.2. Large $\mathrm{CO}_{2}$ Sources of the Alberta Basin and Surrounding Area 


\subsection{Methodology for Estimating $\mathrm{CO}_{2}$ Storage Capacity in Oil and Gas Reservoirs and their Timing of Availability}

This section describes the methodology that has been developed and applied to estimate the effective $\mathrm{CO}_{2}$ storage capacity in depleted oil and gas fields. Additionally, a discussion of the approach for estimating the timing of availability (date of depletion) of these oil and gas reservoirs is also provided.

\subsection{Oil and Gas Reservoir Storage Capacity Calculation Methodology}

The capacity for $\mathrm{CO}_{2}$ storage in oil and gas reservoirs in any particular region is given by the sum of the capacities of all reservoirs in that area, calculated on the basis of reservoir properties, such as original oil or gas in place, recovery factor, temperature, pressure, rock volume, and porosity, as well as in situ $\mathrm{CO}_{2}$ characteristics, such as phase behavior and density. The fundamental assumption being made in these calculations is that the volume previously occupied by the produced hydrocarbons becomes, by and large, available for the storage of $\mathrm{CO}_{2}$. This assumption is generally valid for reservoirs that are not in contact with an aquifer or that are not flooded during secondary and tertiary oil recovery. In reservoirs that are in contact with an underlying aquifer, formation water invades the reservoir as the pressure declines because of production, but $\mathrm{CO}_{2}$ injection can reverse the aquifer influx, thus making pore space available for $\mathrm{CO}_{2}$. However, not all the previous hydrocarbon-saturated pore space will become available for $\mathrm{CO}_{2}$ because some residual water may be trapped in the pore space due to capillarity, viscous fingering, and gravity effects (Stevens et al. 2001).

Another important assumption is that $\mathrm{CO}_{2}$ will be injected into depleted oil and gas reservoirs until the reservoir pressure is brought back to the original, or virgin, reservoir pressure. The results thus obtained represent a conservative estimate because the pressure can generally be raised beyond the original reservoir pressure as long as it remains safely below the threshold rock-fracturing pressure. In this case, the $\mathrm{CO}_{2}$ storage capacity would be higher due to $\mathrm{CO}_{2}$ compression; however, the risk of raising the storage pressure beyond the original reservoir pressure requires a case-by-case reservoir analysis that is not practical for basin-scale evaluations.

Several capacity definitions are being introduced to clarify the meaning of various estimates and the relationships between them. The theoretical capacity assumes that all the pore space (volume) freed up by the production of all recoverable reserves will be replaced by $\mathrm{CO}_{2}$ at in situ conditions. The effective capacity is the more realistic estimate obtained after water invasion, displacement, gravity, heterogeneity, and water-saturation effects have been taken into account. Practical capacity is the storage capacity after consideration of technological limitations, safety, $\mathrm{CO}_{2}$ sources and reservoir distributions, and current infrastructure, regulatory, and economic factors. In the end, all the issues and factors relating to $\mathrm{CO}_{2}$ capture, delivery, and storage contribute to a reduction in the real capacity for $\mathrm{CO}_{2}$ storage in hydrocarbon reservoirs. However, none of these capacity estimates is final, in the sense that these values evolve over time, most likely increasing as new oil and gas discoveries take place, or as better production technologies are developed.

\subsubsection{Theoretical $\mathrm{CO}_{2}$-Storage Capacity}

Only non-associated and associated gas reservoirs are considered in $\mathrm{CO}_{2}$-storage capacity calculations because solution gas is taken into account in oil reservoirs through the oil-shrinkage factor. Since 
reserves databases indicate the volume of original gas in place (OGIP) at surface conditions, the masscapacity for $\mathrm{CO}_{2}$ storage in a gas reservoir at in situ conditions, $\mathrm{MCO}_{2}$, is given by:

$$
\mathrm{MCO}_{2}=\rho \mathrm{CO}_{2} \mathrm{r} \cdot \mathrm{R}_{\mathrm{f}} \cdot\left(1-\mathrm{F}_{\mathrm{IG}}\right) \cdot \mathrm{OGIP} \cdot\left[\left(\mathrm{P}_{\mathrm{s}} \cdot \mathrm{Z}_{\mathrm{r}} \cdot \mathrm{T}_{\mathrm{r}}\right) /\left(\mathrm{P}_{\mathrm{r}} \cdot \mathrm{Z}_{\mathrm{s}} \cdot \mathrm{T}_{\mathrm{s}}\right)\right]
$$

where

$$
\begin{aligned}
\rho \mathrm{CO}_{2} & =\mathrm{CO}_{2} \text { density } \\
\mathrm{R}_{\mathrm{f}} & =\text { recovery factor } \\
\mathrm{F}_{\mathrm{IG}} & =\text { fraction of injected gas } \\
\mathrm{P} & =\text { pressure } \\
\mathrm{T} & =\text { temperature } \\
\mathrm{Z} & =\text { compressibility factor }
\end{aligned}
$$

subscript " $r$ " = reservoir conditions

subscript "s" = surface conditions

The $\mathrm{CO}_{2}$ density at reservoir conditions is calculated from equations of state (e.g., Span and Wagner 1996).

The $\mathrm{CO}_{2}$ storage capacity of single-drive oil reservoirs is calculated similarly to gas reservoirs on the basis of reservoir rock volume (area $[A]$ times thickness $[\mathrm{h}]$ ), porosity $(\varphi)$, and oil saturation $\left(1-S_{\mathrm{w}}\right)$ where $S_{w}$ is the water saturation. For reservoirs flooded with or invaded by water, the volume available for $\mathrm{CO}_{2}$ storage is reduced by the volume of injected and/or invading water $\left(\mathrm{V}_{\mathrm{iw}}\right)$. If water is produced with oil, then the volume available for $\mathrm{CO}_{2}$ storage is augmented by the volume of produced water $\left(\mathrm{V}_{\mathrm{pw}}\right)$. The same mass balance applies in the case of miscible flooding with solvent or gas. Thus:

$$
\mathrm{MCO}_{2}=\rho \mathrm{CO}_{2} \mathrm{r} \cdot\left[\mathrm{Rf} \cdot \mathrm{A} \cdot \mathrm{h} \cdot \varphi \cdot\left(1-\mathrm{S}_{\mathrm{w}}\right)-\mathrm{Viw}_{\mathrm{iw}}+\mathrm{V}_{\mathrm{pw}}\right]
$$

The volumes of injected and/or produced water, solvent, or gas can be calculated from production records. However, the pore volume invaded by water from underlying aquifers cannot be estimated without detailed monitoring of the oil-water interface and detailed knowledge of reservoir characteristics.

\subsubsection{Effective $\mathrm{CO}_{2}$-Storage Capacity}

In the case of reservoirs underlain by aquifers, the reservoir fluid (oil and/or gas) was originally in hydrodynamic equilibrium with the aquifer water. As hydrocarbons are produced and the pressure in the reservoir declines, a pressure differential is created that drives aquifer water up into the reservoir. The amount and rate of water influx is controlled by 1) reservoir permeability and heterogeneity, 2) water expansion in the aquifer, 3 ) pore-volume contraction due to the increase in effective stress caused by the pressure drop in the reservoir, 4) expansion of hydrocarbon accumulations linked to the common aquifer, and 5) artesian flow where the aquifer is recharged by surface water. If $\mathrm{CO}_{2}$ is then injected into the reservoir, the pore space invaded by water may not become available for $\mathrm{CO}_{2}$ storage, resulting in a net reduction of reservoir capacity. The reduced storage volume may eventually become available if the reservoir pressure caused by $\mathrm{CO}_{2}$ injection is allowed to increase beyond the original reservoir pressure, which may or may not always be allowed or possible. Furthermore, the hysteresis effect caused by various mechanisms may also prevent complete withdrawal of invaded water, leading to a permanent loss of storage space.

Analysis of the production history of close to 300 oil and gas pools in western Canada led to the establishment of a set of criteria for determining if an oil or gas reservoir has strong or weak aquifer 
support (Bachu and Shaw 2003, 2005; Bachu et al. 2004) on the basis of pressure history, water production, and cumulative water-gas ratio (WGR) or water-oil ratio (WOR). For oil reservoirs, the gasoil ratio (GOR) was also included in the analysis because, typically, an oil pool with strong aquifer support tends to have a slow pressure decline and flat GOR profile close to solution GOR, and vice-versa. In addition, the production decline versus reservoir pressure was analyzed for these pools. For gas pools, $\mathrm{P} / \mathrm{Z}$ plots were used to identify the presence of aquifer support or lack thereof. The criteria and threshold values for identifying the strength of underlying aquifers are presented in Table 2.1.

Table 2.1. Criteria for Establishing the Strength and Effect of Underlying Aquifers on the $\mathrm{CO}_{2} \mathrm{Storage}$ Capacity in Depleted Oil and Gas Reservoirs in the Western Canada Sedimentary Basin and the Corresponding Storage Capacity Reduction Coefficient

\begin{tabular}{|c|c|c|c|c|}
\hline $\begin{array}{c}\text { Reservoir } \\
\text { Type }\end{array}$ & $\begin{array}{l}\text { WOR }\left(\mathrm{m}^{3} / \mathrm{m}^{3}\right) \text { or } \\
\text { WGR (bbl/MMcf) }\end{array}$ & $\begin{array}{c}\text { GOR } \\
\left(\mathrm{m}^{3} / \mathrm{m}^{3}\right)\end{array}$ & $\begin{array}{l}\text { Aquifer } \\
\text { Strength }\end{array}$ & $\begin{array}{c}\text { Capacity Reduction } \\
\text { Coefficient }\end{array}$ \\
\hline \multirow{4}{*}{ Oil } & $\geq 0.25$ & & \multirow{2}{*}{ Strong } & \multirow{2}{*}{0.50} \\
\hline & $\geq 0.15$ and $<0.25$ & $<1000$ & & \\
\hline & $\geq 0.15$ and $<0.25$ & $\geq 1000$ & \multirow{2}{*}{ Weak } & \multirow{2}{*}{0.97} \\
\hline & $<0.15$ & & & \\
\hline \multirow{2}{*}{ Gas } & $\geq 5.6$ & & Strong & 0.70 \\
\hline & $<5.6$ & & Weak & 0.97 \\
\hline
\end{tabular}

Table 2.1 shows the reduction in $\mathrm{CO}_{2}$ storage capacity for reservoirs with both strong and weak aquifer support. Note that the threshold WGR value for gas reservoirs considered in previous work was $10 \mathrm{bbl} / \mathrm{MMcf}$ (Bachu and Shaw 2005), but additional work and analysis indicates that the value of $5.6 \mathrm{bbl} / \mathrm{MMcf}$ is more appropriate. The storage capacity of reservoirs with weak or no aquifer support is not affected by the presence of the underlying aquifer. However, a very small effect needs to be considered in light of the fact that water is a wetting phase, as opposed to oil and gas, which are nonwetting; hence, it should be expected that some irreducible water would be left behind in the pore space by the receding aquifer. To account for this effect, it is assumed that the theoretical $\mathrm{CO}_{2}$-storage capacity in oil and gas reservoirs with weak aquifer support is reduced by $\sim 3 \%$.

The presence of water in the reservoir also has the effect of reducing the $\mathrm{CO}_{2}$ storage capacity, as discussed previously. Water may be present because of initial water saturation, because of water invasion as the reservoir is depleted, or because it was introduced during secondary and/or tertiary recovery. As a result of capillary forces, irreducible water $\left(S_{\text {wirr }}\right)$ will remain in the reservoir even if the water is "pushed back" by the injected $\mathrm{CO}_{2}$.

All the processes and reservoir characteristics that reduce the actual volume available for $\mathrm{CO}_{2}$ storage can be expressed by capacity coefficients $(C<1)$ in the form (Doughty and Preuss 2004):

$$
\mathrm{M}_{\mathrm{CO} 2 \mathrm{eff}}=\mathrm{C}_{\mathrm{m}} \cdot \mathrm{C}_{\mathrm{b}} \cdot \mathrm{C}_{\mathrm{h}} \cdot \mathrm{C}_{\mathrm{w}} \cdot \mathrm{C}_{\mathrm{a}} \cdot \mathrm{M}_{\mathrm{CO} 2 \mathrm{res}}
$$

where $\mathrm{M}_{\mathrm{CO} \text { eff }}$ is the effective reservoir capacity for $\mathrm{CO}_{2}$ storage, and the subscripts $\mathrm{m}, \mathrm{b}, \mathrm{h}, \mathrm{w}$, and a stand for mobility, buoyancy, heterogeneity, water saturation, and aquifer strength, respectively, and refer to the phenomena discussed previously. These capacity coefficients likely vary over a wide range, depending on reservoir characteristics, and this explains the wide range of incremental oil recovery ( 7 to $23 \%$ of 
OOIP) and $\mathrm{CO}_{2}$ utilization ( 0.7 to $4.7 \mathrm{~m}^{3} \mathrm{CO}_{2} / \mathrm{m}^{3}$ recovered oil at reservoir conditions) observed for $25 \mathrm{CO}_{2}$-flood EOR operations in Texas (Holt et al. 1995). Unfortunately, there are very few studies and methodologies for estimating the values of these capacity coefficients, mostly on the basis of numerical simulations, and generally there are no data or past experience for the specific case of $\mathrm{CO}_{2}$ storage in depleted hydrocarbon reservoirs. The first four capacity coefficients can be captured in a single "effective" coefficient:

$$
\mathrm{C}_{\text {eff }}=\mathrm{C}_{\mathrm{m}} \cdot \mathrm{C}_{\mathrm{b}} \cdot \mathrm{C}_{\mathrm{h}} \cdot \mathrm{C}_{\mathrm{w}}
$$

which can be estimated on the basis of experience with $\mathrm{CO}_{2}$-flood EOR. A review of capacity coefficients for $\mathrm{CO}_{2}$ storage in aquifers suggests that $\mathrm{C}_{\text {eff }}<0.3$. Conditions are more favourable in the case of oil reservoirs (for example, the buoyancy contrast is much reduced), and a value of $\mathrm{C}_{\text {eff }}=0.5$ was considered in this study. For gas reservoirs, $\mathrm{C}_{\mathrm{m}} \approx 1$ because fingering effects are very small to negligible. Because $\mathrm{CO}_{2}$ density is greater than that of methane at reservoir conditions, the $\mathrm{CO}_{2}$ injected in gas reservoirs will fill the reservoir from its bottom. Thus, it can be assumed that $\mathrm{C}_{\mathrm{b}} \approx 1$ as well. The effect of initial water saturation was already implicitly taken into account in the estimates of theoretical ultimate $\mathrm{CO}_{2}$-storage capacity, such that $\mathrm{C}_{\mathrm{w}} \approx 1$ too. Although reservoir heterogeneity may reduce the $\mathrm{CO}_{2}$ storage capacity by leaving pockets of OGIP, $\mathrm{C}_{\mathrm{h}}$ is probably high, approaching values close to unity. Thus, the reduction in $\mathrm{CO}_{2}$ storage capacity for gas reservoirs is much less by comparison with oil reservoirs, and a value of $\mathrm{C}_{\mathrm{eff}}=0.9$ was used in this study.

\subsection{3 $\mathrm{CO}_{2}$ Storage Capacity in Enhanced Oil Recovery}

Carbon dioxide can be used in tertiary EOR in miscible floods if high-purity $\mathrm{CO}_{2}$ is available. Based on the experience gained in the United States, where $\mathrm{CO}_{2}$-EOR has been practiced for more than 30 years at close to 70 oil fields in the Permian Basin of west Texas, a series of technical criteria have been developed for assessing the suitability of oil reservoirs for $\mathrm{CO}_{2}$-EOR and are reviewed and summarized in several publications (Taber et al. 1997; Kovscek 2002; Shaw and Bachu 2002). In assessing the suitability of oil reservoirs in Alberta for $\mathrm{CO}_{2}$-EOR, the following criteria (Shaw and Bachu 2002) were used in previous work:

- Oil gravity greater than $27^{\circ} \mathrm{API}$ and less than $48^{\circ} \mathrm{API}$

- Initial reservoir pressure greater than $7580 \mathrm{kPa}$

- Reservoir temperature less than $121^{\circ} \mathrm{C}\left(250^{\circ} \mathrm{F}\right)$

- Ratio of initial pressure to minimum miscibility pressure (MMP) greater than 0.95 .

An additional, quasi-economic criterion was also used in this work to screen oil reservoirs suitable for $\mathrm{CO}_{2}$-EOR, namely, that the reservoir be sufficiently large to warrant the cost of implementing $\mathrm{CO}_{2}$-EOR. Reservoir size was expressed either by original oil in place (OOIP) of at least $1 \mathrm{MMbl}\left(159,000 \mathrm{~m}^{3}\right)$, or by area, with the requirement that it has to be at least one section in size ( 256 ha) to allow for a 5 -spot pattern with current well spacing regulations. Reservoirs that meet the above set of criteria plus at least one of these other two criteria (i.e., either OOIP $>1 \mathrm{MMbl}$, or area $>256 \mathrm{ha}$ ) are considered suitable for $\mathrm{CO}_{2}$-EOR; otherwise, they were rejected.

The MMP was calculated with the relation (Mungan 1981):

$$
\mathrm{MMP}=-329.558+\left(7.727 \times \mathrm{MW} \times 1.005^{\mathrm{T}}\right)-(4.377 \times \mathrm{MW})
$$


where $\mathrm{T}$ is temperature $\left({ }^{\circ} \mathrm{F}\right)$, and $\mathrm{MW}$ is the molecular weight of the oil $\mathrm{C}_{5+}$ components. In the absence of information in databases about oil composition, the following relation was used to estimate the molecular weight of the $\mathrm{C}_{5^{+}}$components as a function of oil gravity $\mathrm{G}$ expressed in ${ }^{\circ} \mathrm{API}$ (Lasater 1958):

$$
M W=\left(\frac{7864.9}{G}\right)^{\frac{1}{1.0386}}
$$

Reservoir performance and incremental oil recovery were predicted on the basis of information contained in reserves databases using an analytical model developed for this purpose (Shaw and Bachu 2002). The estimated $\mathrm{CO}_{2}$ storage capacity in EOR operations at $\mathrm{CO}_{2}$ breakthrough is a direct result of that model for predicting reservoir performance. Considering that, on average, $40 \%$ of the injected $\mathrm{CO}_{2}$ is recovered at the surface after breakthrough (Hadlow 1992) and assuming that it will be re-injected back into the reservoir, the $\mathrm{CO}_{2}$ storage capacity for any fraction $\mathrm{F}_{\mathrm{i}}$ of hydrocarbon pore volume (HCPV) of injected $\mathrm{CO}_{2}$ was calculated using the following relations:

- At breakthrough (BT),

$$
\mathrm{M}_{\mathrm{CO} 2}=\rho_{\mathrm{CO} 2 \mathrm{res}} \cdot \mathrm{RF}_{\mathrm{BT}} \cdot \mathrm{OOIP} / \mathrm{Sh}
$$

- At any HCPV injection,

$$
\mathrm{M}_{\mathrm{CO} 2}=\rho_{\mathrm{CO} 2 \mathrm{res}} \cdot\left[\mathrm{RF}_{\mathrm{BT}}+0.6 \mathrm{x}\left(\mathrm{RF}_{\% \mathrm{HCPV}}-\mathrm{RF}_{\mathrm{BT}}\right)\right] \cdot \mathrm{OOIP} / \mathrm{Sh}
$$

where

$$
\begin{aligned}
\mathrm{RF}_{\mathrm{BT}}= & \text { recovery factor at breakthrough } \\
\mathrm{RF}_{\% \mathrm{HCPV}}= & \text { recovery factor at the assumed percentage of } \mathrm{HCPV} \text { of injected } \mathrm{CO}_{2} \\
\mathrm{OOIP}= & \text { volume of the original oil in place } \\
\mathrm{Sh}= & \text { oil shrinkage factor }\left(\text { the inverse of the formation volume factor } \mathrm{B}_{0}\right) \\
\rho_{\mathrm{CO} 2 \mathrm{res}}= & \mathrm{CO}_{2} \text { density calculated at reservoir temperature and pressure conditions } \\
& (\mathrm{Span} \text { and Wagner } 1996) .
\end{aligned}
$$

\subsubsection{Practical $\mathrm{CO}_{2}$-Storage Capacity}

The theoretical $\mathrm{CO}_{2}$-storage capacity represents the mass of $\mathrm{CO}_{2}$ that can be stored in hydrocarbon reservoirs, assuming that the volume occupied previously by the produced oil or gas will be occupied in its entirety by the injected $\mathrm{CO}_{2}$. The effective $\mathrm{CO}_{2}$-storage capacity represents the mass of $\mathrm{CO}_{2}$ that can be stored in hydrocarbon reservoirs after taking into account intrinsic reservoir characteristics and flow processes, such heterogeneity, aquifer support, sweep efficiency, gravity override, and $\mathrm{CO}_{2}$ mobility. However, there are also extrinsic criteria that should be considered when implementing $\mathrm{CO}_{2}$ storage in oil and gas reservoirs on a large scale and that further reduce the $\mathrm{CO}_{2}$ storage capacity in oil and gas reservoirs to practical levels.

The storage capacity of oil reservoirs undergoing water flooding is significantly reduced, making it very difficult to assess their $\mathrm{CO}_{2}$ storage capacity in the absence of detailed, specific, numerical simulations of reservoir performance. It is very unlikely that these oil pools, and generally commingled pools, will be used for $\mathrm{CO}_{2}$ storage, at least not in the near future. 
The low capacity of shallow reservoirs, where $\mathrm{CO}_{2}$ would be in the gas phase, may make them uneconomic because of storage inefficiency (Winter and Bergman 1993). On the other hand, $\mathrm{CO}_{2}$ storage in very deep reservoirs could also become uneconomic because of the higher cost of well drilling and of $\mathrm{CO}_{2}$ compression as well as the low "net" $\mathrm{CO}_{2}$ storage $\left(\mathrm{CO}_{2}\right.$ sequestered minus $\mathrm{CO}_{2}$ produced during compression). Thus, Winter and Bergman (1993) recommend considering only reservoirs in a window of 9 to $34.5 \mathrm{MPa}$, which roughly translates to a depth interval of 900 to $3,500 \mathrm{~m}$, as being economic for $\mathrm{CO}_{2}$ storage in depleted hydrocarbon reservoirs.

In terms of $\mathrm{CO}_{2}$ storage capacity, most reservoirs are relatively small in volume and have a low capacity for $\mathrm{CO}_{2}$ storage, rendering them uneconomic. On the other hand, associated oil and gas reservoirs (oil reservoirs with a gas cap) have a $\mathrm{CO}_{2}$ storage capacity that is equal to the sum of the individual capacities of each reservoir. Considering the size of the major stationary $\mathrm{CO}_{2}$-sources, it is most likely that only reservoirs with large $\mathrm{CO}_{2}$-storage capacity will be considered in the short and medium term. Building the infrastructure for $\mathrm{CO}_{2}$ capture, transportation, and injection is less costly if the size of the sink is large enough and if its lifespan is long enough to justify the needed investment and reduce the cost per ton of sequestered $\mathrm{CO}_{2}$. Thus, only reservoirs with individual $\mathrm{CO}_{2}$-storage capacity greater than $5 \mathrm{MtCO}_{2} /$ year were selected at the end of the capacity assessment process. More detailed analysis, based on economic criteria, should be applied for selecting the best oil and gas reservoirs for $\mathrm{CO}_{2}$ storage, among them the timing of their availability for storage (i.e., timing of depletion).

\subsection{Methodology for Estimating Oil and Gas Reservoir Timing of Availability}

Estimating the timing of availability for oil and gas reservoirs is based on a combination of production curves constrained by the remaining recoverable reserves and by economic cut-offs. Based on current economic conditions and the historical performance of oil and gas reservoirs in western Canada, the assumed economic cut-off for gas pools is $100 \mathrm{Mcf} /$ day/well (2.8 thousand $\mathrm{m}^{3} /$ day/well) and $1 \mathrm{bbl} / \mathrm{day} /$ well for oil. Many gas pools have produced by now more gas than originally booked in the reserves databases, and the predicted ultimate recovery of these gas pools has been adjusted accordingly using decline analysis. Conversely, many other gas pools have been abandoned before they recovered the projected recoverable reserves.

The timing of availability (depletion) of both oil and gas reservoirs was estimated using productiondecline analysis and extrapolation by assuming an exponential decline (practice has shown that the tail end of production by and large follows an exponential decline). On a semi-logarithmic plot of production versus time, an exponential decline appears as a straight line with a negative slope. For non-associated gas pools, extrapolating the current production decline up to the point where all the recoverable reserves are produced indicates the timing of reservoir depletion (i.e., availability). For illustration, Figure 2.1 shows that the Blueridge Jurassic B gas pool will reach in 2012 its final recovery value of $2,320 \times 10^{6} \mathrm{~m}^{3}$. The decline analysis can be performed also with the relations:

$$
N_{p}=\frac{365 \times\left(q_{i}-q_{f}\right)}{-\ln (1-d)} \text { and } \quad n=\frac{\ln \left(q_{i} / q_{f}\right)}{-\ln (1-d)}
$$


where

$$
\begin{aligned}
N_{p} & =\text { cumulative production } \\
q & =\text { daily production } \\
d & =\text { effective decline rate } \\
n & =\text { years }\left(N_{p} \text { and } q\right. \text { must have the same units, metric or imperial) } \\
\text { subscript " } T \text { " } & =\text { initial } \\
\text { subscript " } f \text { " } & =\text { final. }
\end{aligned}
$$

For oil pools with no gas cap, knowing the current production and assuming the production at abandonment, the timing of depletion can be estimated by drawing this straight line with such a slope that the area below this straight line equals the remaining recoverable reserves, as illustrated in Figure 2.2 for the Taber North Glauconitic A oil pool that will reach in 2021 its final recovery value of $6,047 \times 10^{3} \mathrm{~m}^{3}$. Estimating the timing of availability for oil reservoirs with an associated gas reservoir (gas cap) is more complex because conservation regulations stipulate that the oil needs to be produced first before the gas can be produced because the gas pressure and expansion provides the necessary drive to oil production. If the gas cap has no commercial value, then the oil reservoir becomes available when all the recoverable oil is produced, like in the case of oil reservoirs with no gas cap. However, when the gas has commercial value, the timing of availability of the oil and/or associated oil reservoirs is the cumulative time of producing both the oil and gas. In the case of a large gas reservoir overlying a large oil reservoir, a part of which is still in primary recovery and another part in secondary or tertiary recovery (water and gas or solvent flooding), the oil has to be produced from the entire oil reservoir before the gas can be produced, extending the time before they are available for $\mathrm{CO}_{2}$ storage. 


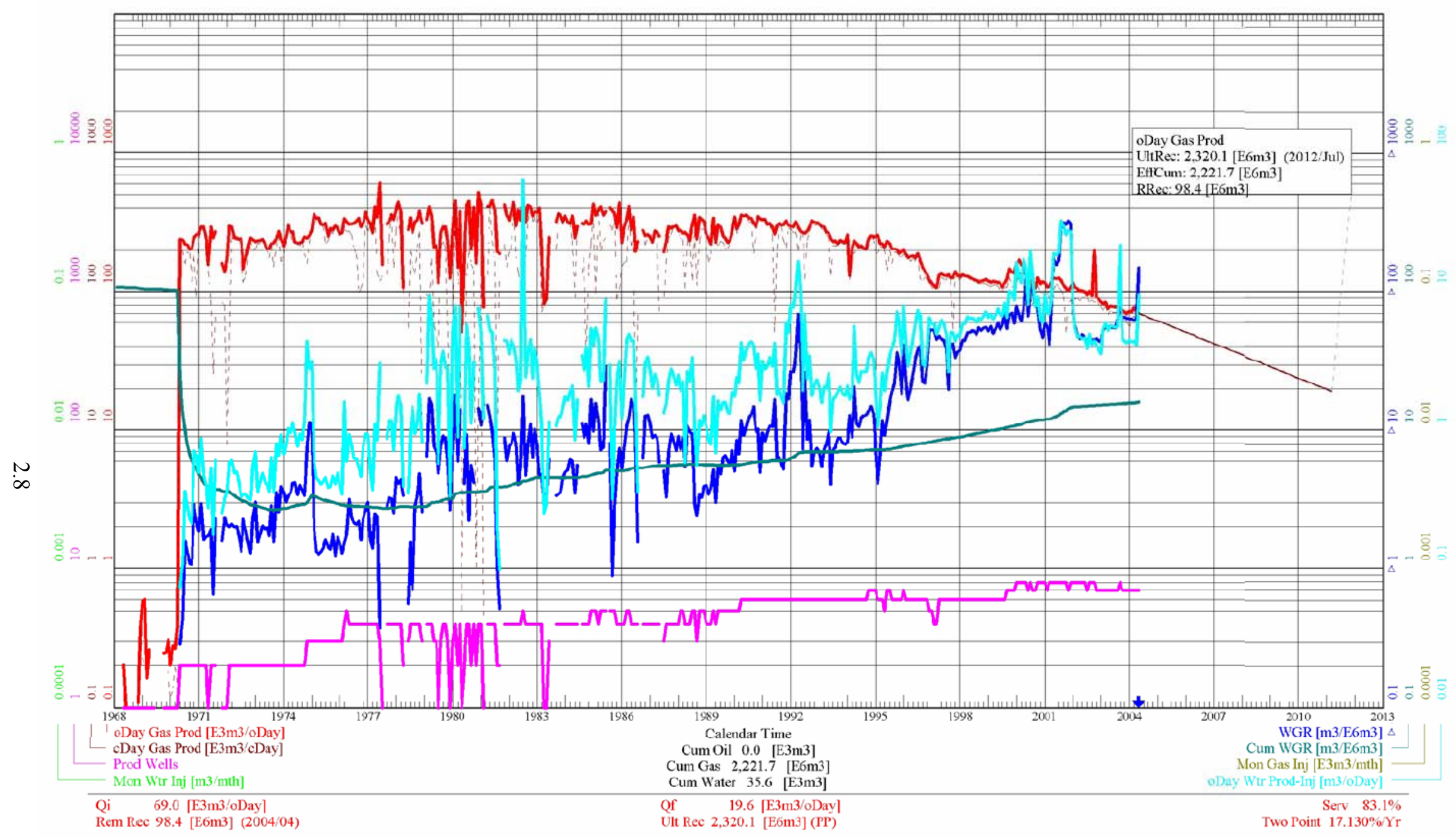

Figure 2.1. Production Decline Analysis for the Blueridge Jurassic B Pool in Alberta 


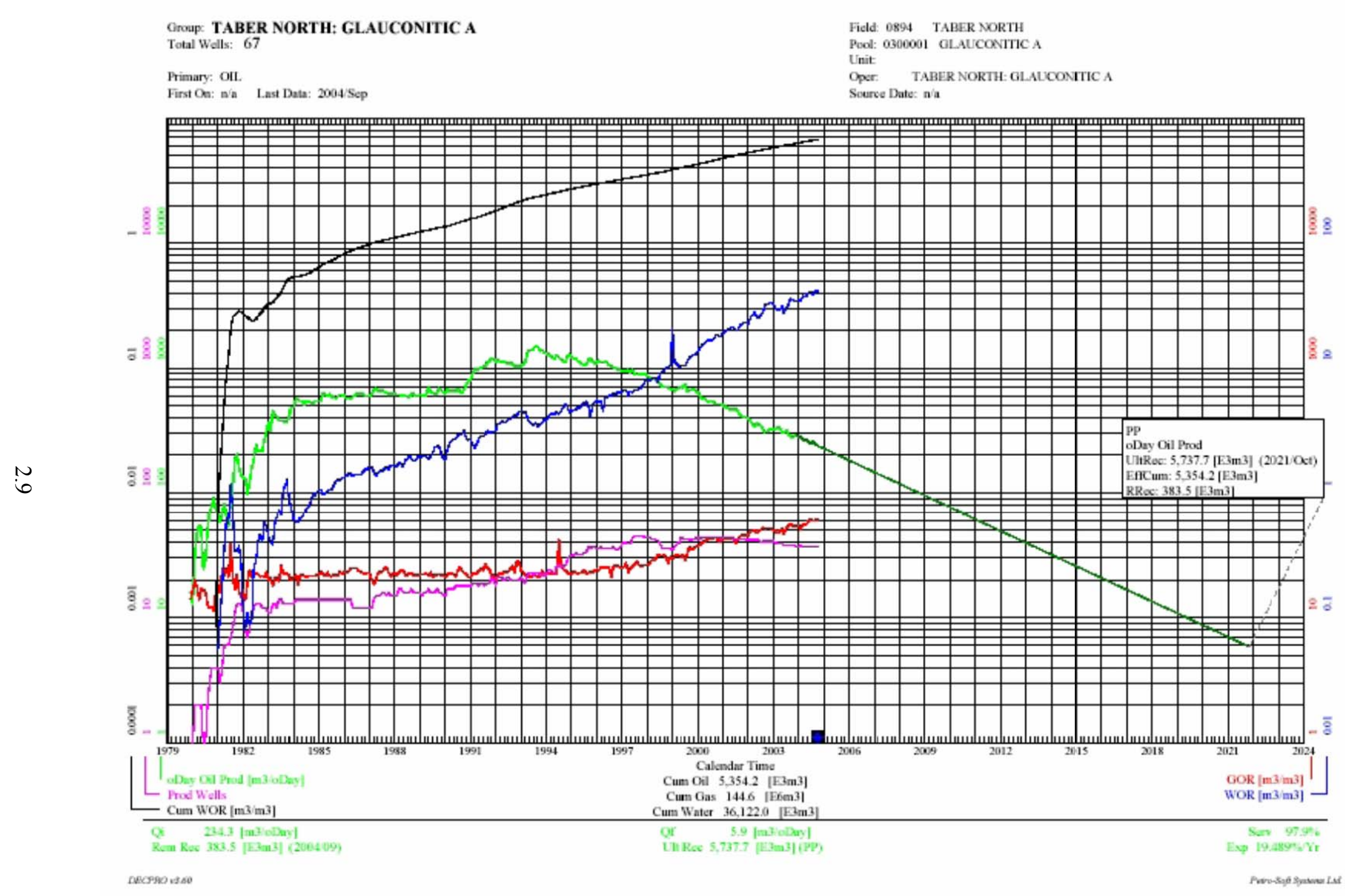

Figure 2.2. Production Decline Analysis for the Taber North Glauconitic A Oil Pools in Alberta 


\subsection{Alberta Basin Data Analysis}

The methodology described in the previous section was applied to the 2004 Alberta and British Columbia oil and gas reserves databases to estimate the $\mathrm{CO}_{2}$ storage capacity in oil and gas reservoirs and identify the pools with sufficiently large capacity to warrant further examination. The process consisted of four main steps:

- checking for the existence of critical data needed in calculations

- calculating the $\mathrm{CO}_{2}$ storage capacity on a reservoir-by-reservoir basis

- identifying the oil pools with an associated gas cap

- estimating the timing of availability (depletion).

\subsection{Oil and Gas Reserves Databases}

The Alberta 2004 oil and gas reserves databases contain a total of 10,438 and 45,726 entries, respectively, differentiated on the basis of field, pool, and mode of production (single drive, primary, flooded, etc.) in the case of oil reservoirs, or sequence in the case of gas reservoirs. In the case of gas pools divided into sequence entities, and in the case of oil pools divided by production mode, the Alberta reserves databases contain also an entry that provides the "Total" reserves for that pool, and these were eliminated from $\mathrm{CO}_{2}$-storage capacity calculations; otherwise, it would double-count the respective capacity. In addition, commingled reservoirs were not considered in this work because no methodology has been developed yet for estimating the combined capacity of pools that produce together.

Furthermore, 1,329 oil reservoirs and 866 gas reservoirs lack critical data necessary for $\mathrm{CO}_{2}$ storagecapacity calculations, such as original oil or gas in place, pressure and/or temperature, etc. The majority of pools that lack pressure data are small pools or new pools that are not yet in production. The OOIP and recoverable reserves of the 1,329 oil pools that lack critical data vary between 3.3 and 10,890 thousands $\mathrm{m}^{3}$ and between 0.1 and 716 thousands $\mathrm{m}^{3}$, respectively, with cumulative OOIP of 258,819 thousands $\mathrm{m}^{3}$ and reserves of 30,109 thousands $\mathrm{m}^{3}$ (average OOIP $=194,894 \mathrm{~m}^{3}$, average $\mathrm{R}_{\mathrm{f}}=11.63 \%$ ). Without knowing the reservoir pressures, it is not possible to calculate $\mathrm{CO}_{2}$ storage capacity, but a conservative estimate (assuming quite high $\mathrm{CO}_{2}$ density) shows that their cumulative $\mathrm{CO}_{2}-$ storage capacity would be less than $20 \mathrm{Mt}$ (less than $16 \mathrm{ktCO}_{2}$ per reservoir). In regard to gas pools, there are 861 gas reservoirs in the 2004 reserves databases that lack the OGIP with seven that lack the recovery factor, and another 5 that lack temperature, initial pressure, and compressibility factors. Thus, no capacity calculations of $\mathrm{CO}_{2}$ capacity can be performed for these 866 gas reservoirs (see relation [1]). The five reservoirs that have OGIP but lack other critical data are very small, with an OGIP of 6, 64, 65, 67, and 142 million $\mathrm{m}^{3}(0.2,2.26,2.3,2.37$, and $5 \mathrm{Bcf})$ and likely with correspondingly small $\mathrm{CO}_{2}$-storage capacity. Thus, neglect of these reservoirs will not affect the final results.

In addition, 552 gas reservoirs were not considered further in capacity calculations, although all the necessary data are available, because they are too shallow $(<100 \mathrm{~m}$ deep $)$, at too low temperature $\left(<10^{\circ} \mathrm{C}\right)$, or at too low initial pressure $(<1000 \mathrm{kPa})$ to be even potentially considered for $\mathrm{CO}_{2}$ storage. These 552 shallow gas reservoirs have a cumulative OGIP of 37,058 million $\mathrm{m}^{3}(\sim 1,305 \mathrm{Bcf})$ and recoverable reserves of 25,244 million $\mathrm{m}^{3}$ ( $\left.\sim 889 \mathrm{Bcf}\right)$. Because they are so shallow, $\mathrm{CO}_{2}$ stored in these reservoirs would be in gaseous phase at low density, and a rough estimate of their capacity indicates that their 
cumulative $\mathrm{CO}_{2}$-storage capacity would be on the order of $50 \mathrm{Mt}\left(0.1 \mathrm{MtCO}_{2}\right.$ each on average). Thus, eliminating these small-capacity shallow gas reservoirs from the storage-capacity estimates will not affect the final results in selecting the top reservoirs with large capacity.

Eliminating the pool summary ("Total") entries from the reserves databases as well as the commingled and very shallow reservoirs and the reservoirs that lack critical data leaves 8,346 oil reservoirs and 30,082 gas reservoirs in Alberta for which $\mathrm{CO}_{2}$ storage capacity was estimated. Table 3.1 shows a breakdown by production type of the oil reservoirs considered in these calculations.

Table 3.1. Type of Oil Production and Corresponding Number of Oil Reservoirs in Alberta's 2004 Reserves Databases

\begin{tabular}{||l|c|}
\hline Reservoir Drive Mechanism & Number of Reservoirs \\
\hline Single drive & 7,754 \\
\hline Primary production in flooded pools & 240 \\
\hline Water flood & 483 \\
\hline Solvent flood & 54 \\
\hline Gas flood & 15 \\
\hline
\end{tabular}

The British Columbia oil reserves database contains 474 entries differentiated on the basis of field, pool, sequence, and project unit. However, only the first three categories identify a physically distinct oil pool, the last one indicating only an administrative unit based on production type. The number of actual oil pools is 414 , of which only 380 have all the data necessary to perform the calculations for determining the $\mathrm{CO}_{2}$ storage capacity. A breakdown of these pools by production type and data existence is given in Table 3.2. Of the 34 oil reservoirs that lack critical data, 18 lack area (some of them are lacking also thickness, water saturation, porosity, and the shrinkage factor), and 16 lack only the shrinkage factor. Those oil pools that are lacking critical data are generally quite small (16 have OOIP $<1 \mathrm{MMbl}, 12$ have OOIP between 1 and $2 \mathrm{MMbl}, 4$ have OOIP between 4 and $7 \mathrm{MMbl}$ ) and very likely have negligible $\mathrm{CO}_{2^{-}}$ storage capacity, considering also the low recovery factor of oil reservoirs. In regard to gas pools, there are 1,832 gas pools in the 2004 reserves database, differentiated by field, pool, and sequence, but only 1,743 of them have all the data needed to calculate $\mathrm{CO}_{2}$ storage capacity.

Table 3.3 shows the range of variability in the data needed for calculating the $\mathrm{CO}_{2}$ storage capacity for the 8,726 oil reservoirs and 31,825 gas reservoirs in the Alberta Basin that have the whole suite of required data for calculating their capacity for storing $\mathrm{CO}_{2}$. Regarding the gas reservoirs, it is worth noting that 97 reservoirs in B.C. have a recovery factor greater than unity, which means that these reservoirs have produced more gas than they were originally estimated to contain. In addition, slightly more than 50 gas reservoirs, mostly in B.C., have a compressibility factor greater than unity, which is an artifact of the way the $\mathrm{Z}$ factor is calculated for reservoirs that contain gas mixtures with a significant fraction of heavier gases. 
Table 3.2. Type and Number of Oil Reservoirs in Northeastern British Columbia as per B.C. 2004 Reserves Database, Showing also the Availability of Critical Data

\begin{tabular}{||l|l|r|r||}
\hline \multirow{3}{*}{ Recovery } & \multicolumn{1}{|c|}{ Production Type } & Number & $\begin{array}{c}\text { Number of Oil } \\
\text { Pools with Data }\end{array}$ \\
\hline \multirow{4}{*}{$\begin{array}{l}\text { Primary } \\
\text { (single drive) }\end{array}$} & Depletion & 255 & 229 \\
\cline { 2 - 4 } & Gas Cap Expansion & 97 & 93 \\
\cline { 2 - 4 } & Gas Injection & 6 & 6 \\
\cline { 2 - 4 } & Gravity & 1 & 1 \\
\cline { 2 - 4 } & Combination & 6 & 5 \\
\hline \multirow{3}{*}{ Secondary } & Waterflood & 44 & 43 \\
\cline { 2 - 4 } & Waterflood and Gas Cap Expansion & 5 & 3 \\
\hline & Total & $\mathbf{4 1 4}$ & $\mathbf{3 8 0}$ \\
\hline
\end{tabular}

Table 3.3. Range of Characteristics of Oil and Gas Pools in the Alberta Basin that Have the Whole Suite of Data Needed for $\mathrm{CO}_{2}$-Storage Capacity Calculations

\begin{tabular}{|c|c|c|c|}
\hline Reservoir Type & Parameter & Minimum & Maximum \\
\hline \multirow[t]{12}{*}{ Oil } & OOIP $\left(10^{3} \mathrm{~m}^{3}\right)$ & 1.6 & 968,700 \\
\hline & Recovery Factor & 0.001 & 0.91 \\
\hline & Depth (m) & 249 & 3,891 \\
\hline & Area (ha) & 1 & 140,992 \\
\hline & Net Pay (m) & 0.23 & 135.7 \\
\hline & Water Saturation & 0.026 & 0.82 \\
\hline & Porosity & 0.01 & 0.35 \\
\hline & Shrinkage Factor & 0.26 & 0.99 \\
\hline & Initial Pressure $(\mathrm{kPa})$ & 1,290 & 61,127 \\
\hline & Temperature $\left({ }^{\circ} \mathrm{C}\right)$ & 11 & 120 \\
\hline & Oil Density $\left(\mathrm{kg} / \mathrm{m}^{3}\right)$ & 695 & 999 \\
\hline & Oil Gravity ( $\left.{ }^{\circ} \mathrm{API}\right)$ & 10 & 72 \\
\hline \multirow[t]{6}{*}{ Gas } & OGIP $\left(10^{6} \mathrm{~m}^{3}\right)$ & 1 & 103,728 \\
\hline & Recovery Factor & 0.08 & 43.17 \\
\hline & Depth (m) & 147 & 6,078 \\
\hline & Initial Pressure $(\mathrm{kPa})$ & 1,000 & 99,625 \\
\hline & Temperature $\left({ }^{\circ} \mathrm{C}\right)$ & 10 & 193 \\
\hline & Compressibility ( $\mathrm{Z}$ factor) & 0.413 & 1.731 \\
\hline
\end{tabular}

In regard to suitability for $\mathrm{CO}_{2}$-EOR, the 552 reservoirs in Alberta that are already water, solvent, or gas flooded were not considered in these $\mathrm{CO}_{2}$-storage capacity estimates. Of the 7,794 reservoirs in Alberta in single drive or primary production, only 1,705 oil reservoirs meet the criteria for suitability for $\mathrm{CO}_{2}$ EOR that were presented previously (see Section 2.3). Similarly, only 118 reservoirs of the 380 oil reservoirs in northeastern B.C. are suitable for $\mathrm{CO}_{2}$ EOR. These 1,823 reservoirs were selected through a process of successive screening in the order presented here, by which, if a reservoir did not meet a 
particular criterion, it was eliminated without further checking it against other criteria. Of the reservoirs that passed all the technical criteria for $\mathrm{CO}_{2}$-EOR suitability (temperature, pressure, MMP, etc.), another 2,400 reservoirs in Alberta and 136 reservoirs in B.C. are too small (OOIP $<1 \mathrm{MMbl}$, or 159,000 $\mathrm{m}^{3}$ ) to make them worthy of consideration. Their cumulative OOIP is less than 200 million $^{3}(\sim 1260 \mathrm{MMbl})$, of which only $\sim 11 \%$ are recoverable. Applying $\mathrm{CO}_{2}$-EOR to these small oil pools will improve recovery and produce more oil, but their cumulative incremental oil production will be too small to be economic. It may well be that these oil reservoirs will be produced in a more distant future after the industry is well established, and an extensive infrastructure for collecting $\mathrm{CO}_{2}$ from major sources and distribution to all these reservoirs is already in place.

\subsection{Calculated $\mathrm{CO}_{2}$ Storage Capacities}

The theoretical $\mathrm{CO}_{2}$-storage capacity at depletion was calculated for all the 31,825 gas reservoirs with data according to relation (1), and for all the 8,085 oil reservoirs in single drive with data according to relation (2). The effective storage capacity was then calculated for all of them according to relations (3) and (4) on the basis of aquifer support as determined according to the criteria presented in Table 2.1. The $\mathrm{CO}_{2}$ storage capacity for flooded oil reservoirs, including the primary production units (Table 3.2), was calculated at the pool level considering the volumes of oil, gas and water produced, and the volume of water injected. In the case of the 54 solvent and 15 gas-flooded reservoirs in Alberta (Table 3.2), it was assumed that the reservoir will be blown down at the end and the solvent or gas will be recovered, given their market value. Consequently, the volumes of injected solvent or gas were not considered in $\mathrm{CO}_{2-}$ storage capacity calculations [relation (2)]. The additional $\mathrm{CO}_{2}$-storage capacity in $\mathrm{CO}_{2}$-EOR was calculated for the 1,823 oil reservoirs that are suitable according to the methodology presented previously, for $50 \% \mathrm{HCPV}$ of injected $\mathrm{CO}_{2}$. After calculations at the individual reservoir level, the $\mathrm{CO}_{2}$-storage capacity estimates were summed at the oil or gas pool level on the basis of field and pool code. The 30,082 gas reservoirs in Alberta collapsed into 27,495 gas pools, and the 8,346 oil reservoirs in Alberta collapsed into 8,095 oil pools. The oil and gas reservoirs in northeastern B.C. are already at the pool level in the B.C. reserves databases. Thus, 29,238 gas pools and 8,475 oil pools were evaluated in the Alberta Basin for their $\mathrm{CO}_{2}$ storage capacity. Table 3.4 presents by pool type the characteristics of their effective $\mathrm{CO}_{2}$-storage capacity.

Table 3.4. Characteristics of $\mathrm{CO}_{2}$ Storage Capacity in Oil and Gas Pools in Alberta

\begin{tabular}{|l|c|c|c|c|c|c||}
\hline \multirow{2}{*}{$\begin{array}{l}\text { Pool } \\
\text { Type }\end{array}$} & \multirow{2}{*}{ EOR Suitable } & \multirow{2}{*}{ No. Pools } & \multicolumn{4}{|c|}{ CO $_{2}$ Storage Capacity (tons) } \\
\cline { 4 - 7 } Oil & Yes & 1,823 & 1,306 & $76,583,337$ & 361,745 & $659,461,178$ \\
\cline { 2 - 7 } & No & 6,652 & $\sim 1$ & $20,325,833$ & 24,718 & $164,425,862$ \\
\cline { 2 - 7 } & All & 8,475 & $\sim 1$ & $76,583,337$ & 97,214 & $823,877,040$ \\
\hline Gas & - & 29,238 & 128 & $124,543,649$ & 318,227 & $9,304,337,267$ \\
\hline All & & 37,713 & $\sim 1$ & $124,543,649$ & 268,560 & $10,128,214,317$ \\
\hline
\end{tabular}

Examination of Table 3.4 shows that the $\mathrm{CO}_{2}$ storage capacity in gas reservoirs in the Alberta Basin is one order of magnitude greater than that of oil reservoirs, although they are only approximately 3.4 times as many. This is due mainly to much larger recovery factors for gas reservoirs than for oil reservoirs. The $\mathrm{CO}_{2}$ storage capacity in the 6,652 oil pools that are not suitable for $\mathrm{CO}_{2}$-EOR is quite small, with an 
average of only $\sim 25 \mathrm{ktCO}_{2}$ per pool, for a total of slightly less than $165 \mathrm{MtCO}_{2}$. Of these pools, 222 are flooded with no storage capacity left as a result of water injection, while 277 flooded pools still have storage capacity remaining, cumulatively estimated at slightly less than $100 \mathrm{MtCO}_{2}$. However, as water flooding continues, their $\mathrm{CO}_{2}$ storage capacity will diminish.

The additional $\mathrm{CO}_{2}$-storage capacity in the 1,705 oil reservoirs in Alberta that are suitable for $\mathrm{CO}_{2}$-EOR is considerable, but 91 are already flooded (secondary or tertiary recovery). Only $25 \%\left(165.9 \mathrm{MtCO}_{2}\right)$ of the $\mathrm{CO}_{2}$ storage capacity originates in the pore space that would become available at depletion, with the other $\sim 75 \%\left(486.6 \mathrm{MtCO}_{2}\right)$ being the result of EOR at 50\% $\mathrm{HCPV} \mathrm{CO}_{2}$ injection. Actually, the estimate of $\mathrm{CO}_{2}$ storage capacity in EOR in these 1,705 reservoirs is greater than the $\mathrm{CO}_{2}$ storage capacity at depletion $\left(325.4 \mathrm{MtCO}_{2}\right)$ in all 8,095 oil pools in Alberta. In contrast, the additional $\mathrm{CO}_{2}$-storage capacity in $\mathrm{CO}_{2}$-EOR in the 118 oil reservoirs in northeastern B.C. that are suitable for $\mathrm{CO}_{2}$-EOR is small, varying between 13.5 and $800 \mathrm{kt} \mathrm{CO}_{2}$, except for two reservoirs whose additional $\mathrm{CO}_{2}$-storage capacity is $\sim 1.5$ and $\sim 1.8 \mathrm{Mt} \mathrm{CO}_{2}$, respectively. The cumulative additional $\mathrm{CO}_{2}$-storage capacity in these 118 oil reservoirs in northeastern B.C. is in the order of $16.2 \mathrm{Mt} \mathrm{CO}_{2}$.

In the case of associated oil and gas pools, the combined $\mathrm{CO}_{2}$-storage capacity of each oil and associated gas pool is the sum of the respective capacities. A total of 1,478 oil pools in Alberta have an associated gas pool (gas cap) (i.e., 6,617 oil pools and 26,017 gas pools are not associated with a gas or an oil pool, respectively). Thus, according to the 2004 Alberta reserves database, the total number of individual, notcommingled hydrocarbon pools with the necessary data for estimating their $\mathrm{CO}_{2}$ storage capacity is 34,112 , and their cumulative storage capacity is estimated to be in the order of $7.8 \mathrm{GtCO}_{2}$, of which $\sim 7 \mathrm{GtCO}_{2}$ capacity is in gas pools. In northeastern B.C., there are 124 oil pools with an associated gas cap, 256 oil reservoirs, and 1,619 non-associated gas reservoirs (i.e., 1,999 hydrocarbon pools that are not commingled). The $\mathrm{CO}_{2}$ storage capacity in gas reservoirs in northeastern B.C. is $\sim 2.3 \mathrm{GtCO}_{2}$ while the storage capacity in oil reservoirs is negligible at close to $12 \mathrm{MtCO}_{2}$. By combining the oil pools with associated gas caps into a single pool, the number of distinct, non-commingled hydrocarbon pools in the Alberta Basin reduces to 36,111.

The $\mathrm{CO}_{2}$ storage capacity of the great majority of the 36,111 hydrocarbon pools in the Alberta Basin that are not commingled is, however, small, as indicated by their average of $0.28 \mathrm{MtCO}_{2}$. Only 886 hydrocarbon pools in Alberta have an individual capacity greater than $1 \mathrm{MtCO}_{2}$ each (average $5.4 \mathrm{MtCO}_{2}$ ). These pools, which represent $2.6 \%$ of all the pools, have a cumulative $\mathrm{CO}_{2}$-storage capacity of $\sim 4.7 \mathrm{GtCO}_{2}\left(60 \%\right.$ of the total), of which $4.2 \mathrm{GtCO}_{2}$ capacity is in gas pools. Figure 3.1 shows the histogram of the $\mathrm{CO}_{2}$ storage capacity in the 886 oil and gas pools with $\mathrm{CO}_{2}$ storage capacity greater than $1 \mathrm{MtCO}_{2}$, indicating that the great majority of oil and gas in Alberta with a large capacity $\left(>1 \mathrm{MtCO}_{2}\right)$ are still comparatively small and that indeed a very small number of oil and gas pools have a very large capacity. 


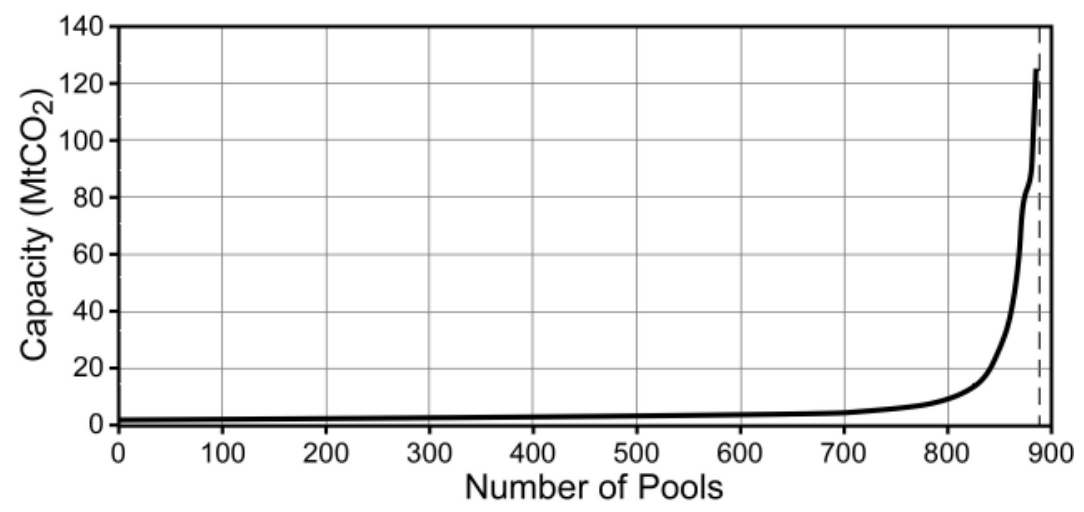

Figure 3.1. Histogram of the Oil and Gas Pools in Alberta with Individual Storage Capacity Greater than $1 \mathrm{MtCO}_{2}$

There are 145 hydrocarbon pools in Alberta with individual storage capacity greater than $5 \mathrm{MtCO}_{2}$ each (average of $23.1 \mathrm{MtCO}_{2}$, cumulative total of $\sim 3.35 \mathrm{GtCO}_{2}$ ). These 145 pools represent $0.43 \%$ of the total $\mathrm{CO}_{2}$ storage capacity in Alberta, yet they possess $43.6 \%$ of the $\mathrm{CO}_{2}$ storage capacity in non-commingled oil and gas pools in Alberta. The largest $\mathrm{CO}_{2}$-storage capacity is in gas pools $\left(2,983 \mathrm{MtCO}_{2}\right)$, with the remainder of $\sim 355 \mathrm{MtCO}_{2}$ in oil pools (of which only $\sim 113 \mathrm{MtCO}_{2}$ at depletion). Seven oil pools have no gas cap and 34 oil pools have an associated gas pool. The remaining 104 are non-associated gas pools. Twelve of the 34 oil pools with associated gas pools are not suitable for $\mathrm{CO}_{2}$-EOR, and the other 22 are. Of these 12, four are already flooded, with two of them with no storage capacity left in the oil pool, only in the overlying gas pool. Water injection likely is at the expense of pore space in the gas reservoir, and as flooding continues, the $\mathrm{CO}_{2}$ storage capacity will diminish. Six of the 22 associated oil pools that are suitable for $\mathrm{CO}_{2}$-EOR are also currently flooded. Applying $\mathrm{CO}_{2}$-EOR to the 29 associated and nonassociated oil reservoirs that are or are not currently flooded requires different strategies.

In northeastern B.C., only 353 pools have $\mathrm{CO}_{2}$ storage capacity greater than $1 \mathrm{MtCO}_{2}$, for a total $\mathrm{CO}_{2}$ storage capacity of more than $1.9 \mathrm{GtCO}_{2}$ (i.e., $\sim 18 \%$ of hydrocarbon pools possess $83.6 \%$ of the total $\mathrm{CO}_{2}$ storage capacity), with a reservoir average of $5.47 \mathrm{MtCO}_{2}$. There is only one oil reservoir among the 353 pools with a capacity of $\sim 1 \mathrm{MtCO}_{2}$. Thirty other oil pools actually underlie a gas pool, but the $\mathrm{CO}_{2}$ storage capacity in all these 31 oil pools is only $0.3 \%$ of the total capacity in all 353 pools (i.e., absolutely negligible when compared with the storage capacity in gas reservoirs). Figure 3.2 shows a histogram of the $\mathrm{CO}_{2}$ storage capacity in these large pools in northeastern B.C. It is worth noting that 82 gas reservoirs have a storage capacity greater than $5 \mathrm{MtCO}_{2}$ each, but cumulatively they have a capacity of $1,436 \mathrm{MtCO}_{2}$. Although they represent $\sim 4 \%$ of the oil and gas reservoirs in northeastern British Columbia, these reservoirs contain $\sim 64.5 \%$ of the $\mathrm{CO}_{2}$ storage capacity in northeastern British Columbia. The storage capacity in oil reservoirs that underlie eight of these gas reservoirs is negligible at $\sim 20 \mathrm{ktCO}_{2}$. 


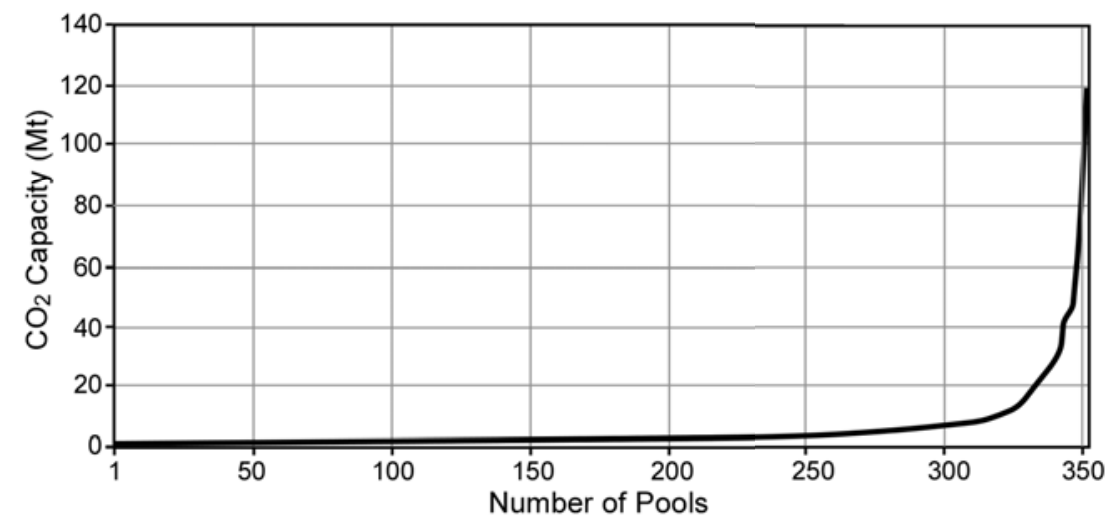

Figure 3.2. Histogram of the Oil and Gas Pools in Northeastern British Columbia with Individual Storage Capacity Greater than $1 \mathrm{MtCO}_{2}$

\subsection{Summary of Storage Capacity Analysis}

This analysis shows that 227 out of 36,111 oil and gas pools in the Alberta Basin $(<1 \%$ of all pools) have an individual $\mathrm{CO}_{2}$ storage capacity of at least $5 \mathrm{MtCO}_{2}$. These pools possess an estimated cumulative $\mathrm{CO}_{2}$ storage capacity of $4,785 \mathrm{MtCO}_{2}$ compared to the total of $\sim 10 \mathrm{GtCO}_{2}$ (i.e., $46 \%$ of the total capacity) for the entire basin.

Table 3.5 lists the number of pools and estimated $\mathrm{CO}_{2}$ storage potential by pool type, and Figure 3.3 shows the location of these large-capacity hydrocarbon pools within the Alberta Basin. The majority of these 227 pools with very large $\mathrm{CO}_{2}$ storage capacity are gas reservoirs (178), with only 7 oil pools and 42 oil pools with an associated gas cap. The non-associated gas pools have a cumulative capacity of 3,440 $\mathrm{MtCO}_{2}$, compared with only $147 \mathrm{MtCO}_{2}$ for the 7 oil pools and 1,198 $\mathrm{MtCO}_{2}$ for the 42 oil pools with an associated gas cap. The $\mathrm{CO}_{2}$ storage capacity in the oil leg of associated oil and gas pools is actually small at $220 \mathrm{MtCO}_{2}$, with most of the storage capacity $\left(978 \mathrm{MtCO}_{2}\right)$ being provided by the gas pools. However, the underlying oil pool affects the timing of availability because the oil pool has to be produced first. Twenty-seven oil pools are suitable for $\mathrm{CO}_{2}$-EOR, with an estimated oil recovery at 50\% $\mathrm{HCPV} \mathrm{CO} 2$ injection of $\sim 113 \times 10^{6} \mathrm{~m}^{3}$ (709 MMbl).

Table 3.5. Summary of Alberta Basin Oil and Gas Pools by Type, Quantity, and Estimated $\mathrm{CO}_{2}$ Storage Capacity $\left(\mathrm{MtCO}_{2}\right)$

\begin{tabular}{|l|c|c||}
\hline Type of Reservoir & Number of Pools & $\begin{array}{c}\text { Total CO } \mathbf{C O}_{2} \text { Storage } \\
\text { Capacity (MtCO }\end{array}$ ) \\
\hline Oil Pools & 7 & 147 \\
\hline Gas Pools & 178 & 3,440 \\
\hline Associated Oil \& Gas & 42 & 1,198 \\
\hline TOTAL & $\mathbf{2 2 7}$ & $\mathbf{4 , 7 8 5}$ \\
\hline
\end{tabular}


These oil and gas pools with very large $\mathrm{CO}_{2}$ storage capacity should be the primary target for $\mathrm{CO}_{2}$ geological storage in the basin. Accordingly, their timing of availability (i.e., depletion), was calculated according to the methods described previously. In the case of oil reservoirs suitable for $\mathrm{CO}_{2}$-EOR, the timing of availability is still considered the timing of depletion, although EOR operations may start sooner.

Most of the oil and gas pools with very large capacity for $\mathrm{CO}_{2}$ storage are located in a band approximately 150 to $200 \mathrm{~km}$ wide parallel to the Rocky Mountains (Figure 3.3). There are many potential storage sites southwest of Edmonton and along the Edmonton-Calgary corridor, which provides lots of $\mathrm{CO}_{2}$ storage opportunities for the large $\mathrm{CO}_{2}$ emitters in these regions (Figure 1.2). Forty-seven of the 227 pools with a capacity greater than $5 \mathrm{MtCO}_{2}$ each are located in the Thrust and Fold belt of the Rocky Mountains where access is more difficult, and these potential sinks most likely will be used at a later stage when infrastructure will be in place. The other 180 pools with very large $\mathrm{CO}_{2}$ storage capacity are located in the undeformed part of the Alberta Basin where access is easier. There are good $\mathrm{CO}_{2}-$ storage opportunities in southeastern Alberta and northeastern British Columbia as well, but much fewer in northeastern Alberta, and none within a 100-km distance of the oil-sands plants in the Fort McMurray area. Carbon dioxide emissions from the oil-sands plants will have to be pipelined to the south and southwest. 


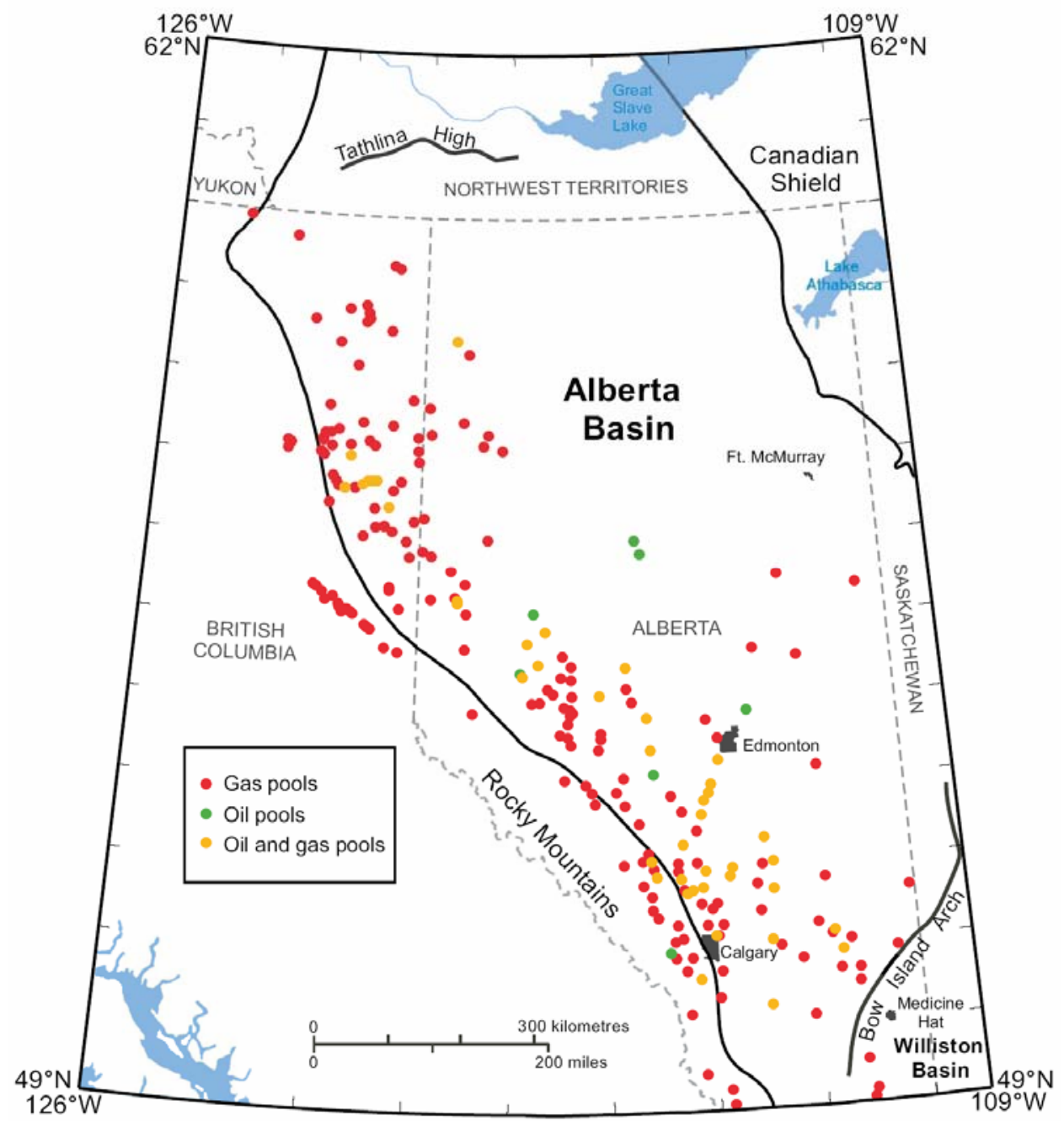

Figure 3.3. Map of 227 Largest Oil and Gas Reservoirs in Alberta Basin (each $>5 \mathrm{MtCO}_{2}$ )

The depth of the 227 oil and gas pools with large $\mathrm{CO}_{2}$-storage capacity varies between $380 \mathrm{~m}$ and $4,875 \mathrm{~m}$, with the shallower pools (less than $900 \mathrm{~m}$ ) located mostly in the northeastern part of the basin (Figure 3.3), and the deep pools along the Rocky Mountains. The location and depth of these 227 pools will undoubtedly affect strategies for matching large $\mathrm{CO}_{2}$ sources with $\mathrm{CO}_{2}$ sinks. This depth range is wider than the range of $900 \mathrm{~m}$ to 3,500 $\mathrm{m}$ recommended in the literature (Winter and Bergman 1993), with 19 pools shallower than $900 \mathrm{~m}$ (16 in Alberta and 3 in B.C.) and 17 pools deeper than 3,500 $\mathrm{m}$ (15 in Alberta and 2 in B.C.). Only one of these 36 pools out of the recommended depth range is an oil pool at $\sim 3540 \mathrm{~m}$ depth, with all the other being non-associated gas pools. The cumulative $\mathrm{CO}_{2}$-storage capacity of the 36 pools that are at depths outside the previously recommended range is $\sim 813 \mathrm{MtCO}_{2}(\sim 63 \%$ of which is in the deep pools and $37 \%$ in the shallow pools), which is considerable and should not be disregarded. Even if shallower pools have low storage efficiency (amount of $\mathrm{CO}_{2}$ stored in a unit of rock volume), their sheer size provides significant capacity to make them economic. Furthermore, many shallow pools are located in the northeastern part of the Alberta Basin, closer to the oil-sands plants in the Athabasca area, and these pools may provide storage capacity for emissions from these plants at least for a period of time at the beginning of large-scale implementation of $\mathrm{CO}_{2}$ storage in Alberta. Disregarding 
these potential $\mathrm{CO}_{2}$ sinks would mean that the $\mathrm{CO}_{2}$ would have to be pipelined a greater distance. In regard to deep pools, their size may make them economic even if more energy is needed for compression if the alternative solution to using them is transportation to another site, farther away, in which case there would be need for additional energy for pipelining the $\mathrm{CO}_{2}$. Thus, rather than excluding these pools a priori, their potential for $\mathrm{CO}_{2}$ storage should be considered on a case-by-case basis in relation to their proximity to large $\mathrm{CO}_{2}$ sources and overall economics.

\subsection{Timing of Availability}

The timing of availability was assessed for each of these oil and gas pools within the Alberta Basin, based on the methodology described in the previous section. Results of the timing of availability for the largest capacity pools (those with individual capacity $>5 \mathrm{MtCO}_{2}$ ) are shown in Figure 3.4. This figure plots the total $\mathrm{CO}_{2}$ storage capacity in depleted oil and gas reservoirs that is expected to come online each year over the next six decades, by pool type. A number of 28 pools with a total storage capacity of $\sim 514 \mathrm{MtCO}_{2}$ are already depleted, and $\mathrm{CO}_{2}$ storage could now begin in these pools. In general, over half of the anticipated storage capacity is expected to become available by about 2020, with much of the rest by 2040. The last pool is estimated to be available for $\mathrm{CO}_{2}$ storage in 2062 .

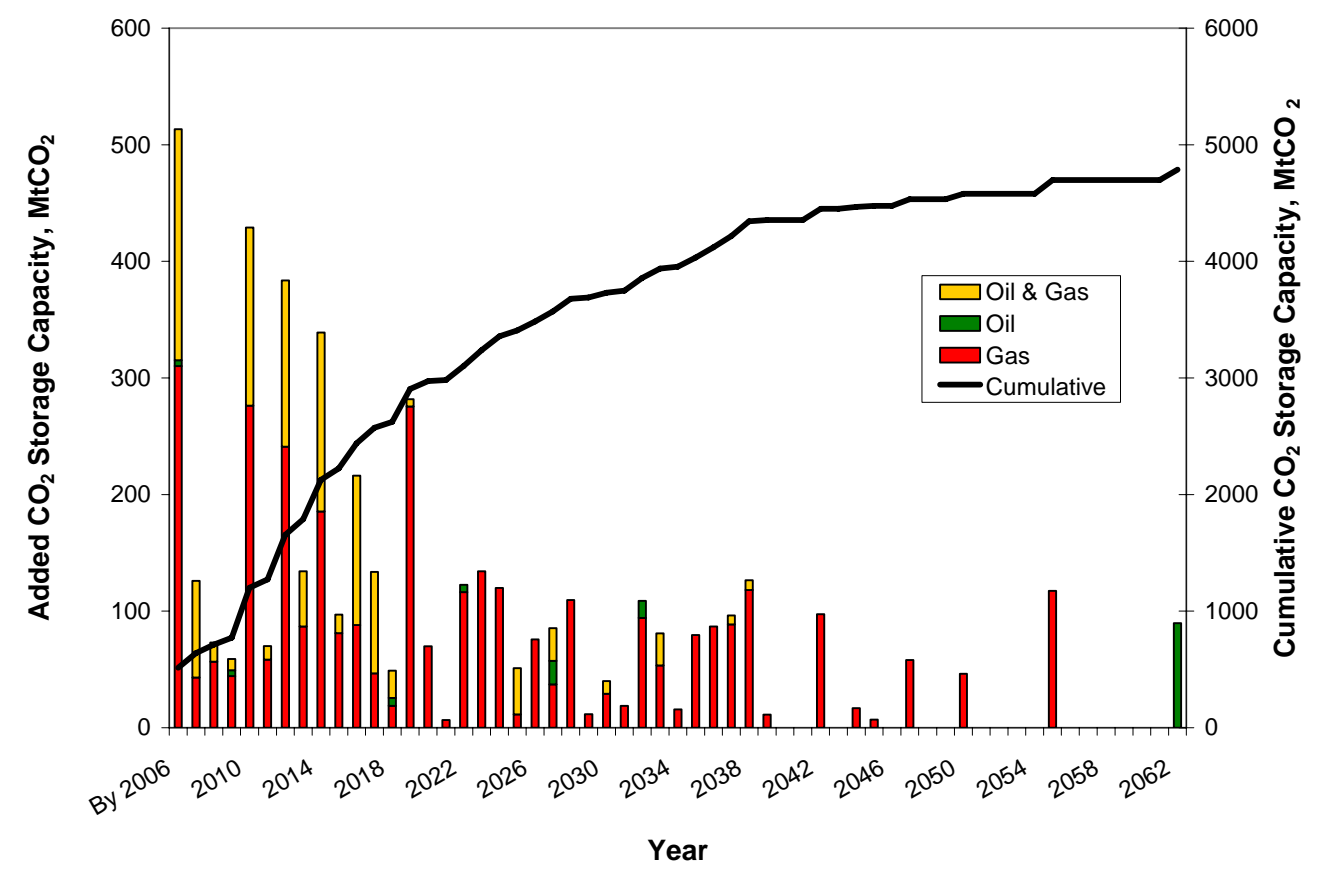

Figure 3.4. Histogram of Timing of Availability for the 227 Pools in the Alberta Basin with very Large $\mathrm{CO}_{2}$-Storage Capacity ( $>5 \mathrm{MtCO}_{2}$ each): by $\mathrm{CO}_{2}$ Storage Capacity that Will Become Available Annually, and Cumulative $\mathrm{CO}_{2}$-Storage Capacity over Time 


\subsection{Source-Reservoir Matching and Cost Curve Methodology}

The data analysis described in the previous two sections has provided new estimates for the $\mathrm{CO}_{2}$ storage capacity of the 227 largest oil and gas pools within the Alberta Basin of western Canada. Additionally, the first-ever basin-scale timing of depletion estimates allow for a schedule of $\mathrm{CO}_{2}$ resource availability to be created, indicating when each part of the cumulative $4,785 \mathrm{MtCO}_{2}$ of storage capacity is expected to become available for use. While valuable in its own right, the true worth of these data is revealed when used to examine the likely market utilization of this storage capacity within the region. Just because there is storage available at a given point in time does not mean that it offers any real value to the region's economy, via offering an economic or practical storage option to the large $\mathrm{CO}_{2}$ sources of the region. This section describes the source-reservoir matching and cost curve methodology that will be used to further examine the impact of the storage capacity and timing of availability of these 227 large oil and gas pools in relation to other potentially viable $\mathrm{CO}_{2}$ storage options within the region. Techno-economic and geospatial tools enable an assessment of the potential value that these candidate storage formations offer, along with other types of reservoirs, and provide insight into the potential infrastructure development needs to support a large-scale CCS deployment. Preliminary results/findings from initial analyses are also presented.

\subsection{Techno-Economic Geospatial Modeling}

As discussed in Chapter 1, there are 81 large $\mathrm{CO}_{2}$ point sources located within the Alberta Basin with cumulative annual emissions of about $120 \mathrm{MtCO}_{2}$. These large stationary sources of $\mathrm{CO}_{2}$ may soon look to CCS technology to help mitigate their emissions. What $\mathrm{CO}_{2}$ storage options do they have and which are they likely to select?

According to the results presented in the previous chapter, there are 227 oil and gas pools within the basin with individual capacities of at least $5 \mathrm{MtCO}_{2}$ and a total combined capacity of $4,785 \mathrm{MtCO}_{2}$. However, in addition to the oil and gas pools of the region, previous analyses (e.g., IEA GHG 2005) have also documented the large $\mathrm{CO}_{2}$ storage resource provided by deep saline formations and uneconomic coal seams within the Alberta Basin. Deep saline formations are ubiquitous throughout most of the region and offer several hundreds of $\mathrm{GtCO}_{2}$ of potential storage capacity. Unmineable coal beds located in the south-southwest of Alberta may provide another $1 \mathrm{GtCO}_{2}$ storage capacity (Bachu and Lytviak 2005) if this technology proves technically viable. Figure 4.1 is a map of the region showing the locations of the large $\mathrm{CO}_{2}$ point sources in relation to the oil and gas pools, deep saline formations, and unmineable coal seams that might be usable targets for $\mathrm{CO}_{2}$ storage. Note that the relative storage capacity of each oil and gas pool is indicated by the size of the symbol and the vast territory that is underlain by the deep saline formation. The coal seams are somewhat difficult to see, but are present along the southwestern edge of Alberta. 


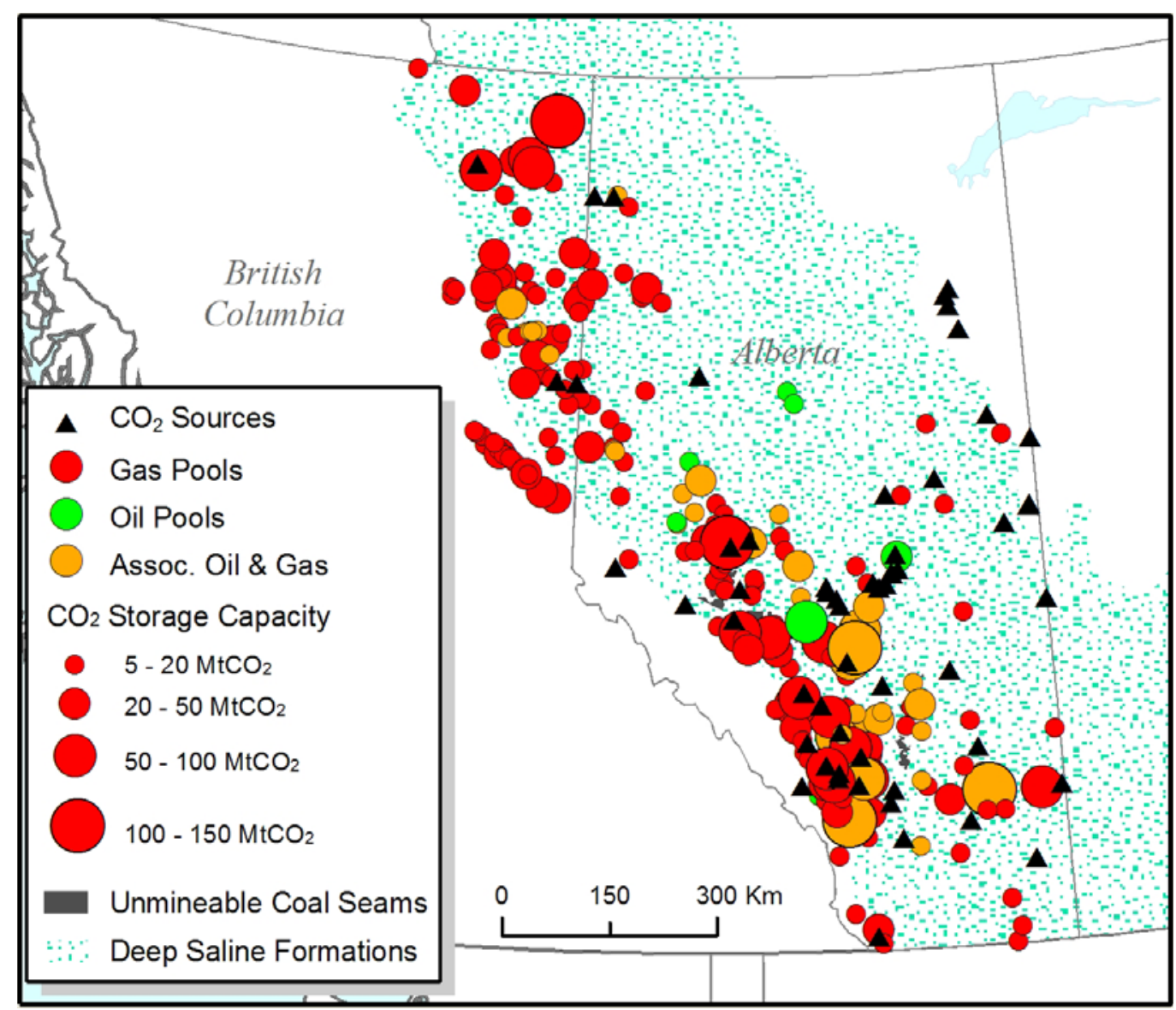

Figure 4.1. Location of the Large $\mathrm{CO}_{2}$ Point Sources ( $>100 \mathrm{ktCO}_{2} /$ year) and the 227 Oil and Gas Pools in the Alberta Basin with the Largest $\mathrm{CO}_{2}$ Storage Capacity ( $>5 \mathrm{MtCO}_{2}$ each), plus the Location of Deep Saline Formations and Unmineable Coal Seams (south-southwest Alberta)

To examine the impact that the storage capacity of the depleted oil and gas reservoirs may have on the region, and in particular the resulting schedule indicating when the capacity resource might become available for $\mathrm{CO}_{2}$ storage, an existing source-reservoir matching methodology is applied. The Battelle $\mathrm{CO}_{2}-\mathrm{GIS}^{(\mathrm{a})}$ is a tool that was specifically built for the purpose of gaining insight into the potential for CCS technologies to deploy across regions of North America in a competitive marketplace for cost-effective emissions reductions. It considers the key characteristics of a region's $\mathrm{CO}_{2}$ sources and candidate $\mathrm{CO}_{2}$ storage reservoirs in a cost-minimizing process matching sources and sinks and allocating storage capacity commitments. Costs of $\mathrm{CO}_{2}$ transport via pipeline and storage into each selected reservoir are estimated for each possible combination of source and reservoir within a specified maximum distance, and the resulting least-cost scenario is output as a regional $\mathrm{CO}_{2}$ supply curve.

(a) GIS = Geographic Information System 


\subsubsection{The Battelle $\mathrm{CO}_{2}$-GIS}

The core of the Battelle $\mathrm{CO}_{2}$-GIS modeling framework consists of a GIS-enabled matching algorithm of the identified point sources with candidate storage reservoirs. Integrated economic-analysis features allow the examination of the major CCS component costs for each identified source-reservoir pair. Therefore, incorporating the latest Alberta Basin source and reservoir data into the Battelle $\mathrm{CO}_{2}-\mathrm{GIS}$, a series of pair-wise costs can be calculated that account for the transportation of $\mathrm{CO}_{2}$ from the plant gate of the anthropogenic $\mathrm{CO}_{2}$ source and the net cost of storing it in each of the available candidate reservoirs within a maximum specified distance. ${ }^{\text {(a) }}$ This process generates a suite of potential costs for storing these point sources' $\mathrm{CO}_{2}$ within the candidate $\mathrm{CO}_{2}$ storage formations. ${ }^{(b)}$ For the set of sources and reservoirs considered here, nearly 1,500 possible combinations (and, therefore, prices) are generated when the search radius is set to 100 miles $(161 \mathrm{~km})$. From this large population of potential costs, the model selects the minimum cost from each source-reservoir combination, thus generating a storage cost curve for the set of sources considered.

A key component of this research is to apply a methodology that allows for a better understanding of how the market-based demand for $\mathrm{CO}_{2}$ storage capacity would develop within the Alberta Basin. The goal is to apply a cost methodology equipped to model the interplay between these 81 large point sources and the large but finite identified storage capacity. This market-based dynamic between sources seeking storage capacity and candidate $\mathrm{CO}_{2}$ storage reservoirs offering storage capacity is represented by an economic modeling framework that explicitly calculates a series of pair-wise cost-minimizing decisions for these $\mathrm{CO}_{2}$ sources and potential geologic storage reservoirs. This economic model explicitly represents the cost of transporting $\mathrm{CO}_{2}$ from the plant gate to a selected storage reservoir, the cost of injecting it into the underground formation, and any offsetting revenue associated with resulting enhanced hydrocarbon recovery. For the purposes of this study, the cost of capture was specifically not considered to allow for a clear focus on the storage side of CCS economics.

Within the Alberta Basin, it is assumed that land-based pipelines will most likely be the preferred method of $\mathrm{CO}_{2}$ transport, particularly for the large volumes of $\mathrm{CO}_{2}$ that would be required under the assumptions of this analysis. Cost estimates for the $\mathrm{CO}_{2}$ pipeline model were developed based on 10 years of land construction costs for natural gas pipelines in the U.S. and Canada, as reported to regulatory filing agencies (True 2002). The size (i.e., diameter) and, therefore, the cost of the $\mathrm{CO}_{2}$ pipeline is based upon the total expected flow rate, which will be a function of the size of the point source and resulting $\mathrm{CO}_{2}$ flow rate.

The storage cost model estimates the net cost of $\mathrm{CO}_{2}$ storage activities, including site preparation and surface facilities, well drilling and completing, operations and maintenance, and $\mathrm{CO}_{2}$ monitoring. Key variables include reservoir type, depth, and likely injectivity, as well as the $\mathrm{CO}_{2}$ mass flow rate from the source. For value-added storage reservoirs (such as oil fields with potential for EOR or coal seams with

(a) The cost of $\mathrm{CO}_{2}$ capture from the source and compression before transport can also be included in the analysis; however, to maintain a focus on the characteristics of the storage reservoirs and their distance from the sources, these factors have been excluded from this analysis at this time.

(b) A description of the economic costing functionality of the Battelle $\mathrm{CO}_{2}$-GIS, which was used to perform the pair-wise transport cost analyses, has been previously published in Dahowski and Dooley (2004). 
potential for enhanced coal-bed methane $[\mathrm{ECBM}]$ recovery), production well costs, hydrocarbon recovery factors, and oil and gas prices are also provided. ${ }^{(\text {a) }}$

Capital costs are combined with annual operating, maintenance, and monitoring costs (along with any expected revenue from value-added reservoirs), and are levelized to arrive at a net cost in dollars per ton of $\mathrm{CO}_{2}$ stored. This is combined with similar costs for capture and transport to create the total levelized net CCS cost estimate.

In addition to source-reservoir matching and costing capability, the $\mathrm{CO}_{2}$-GIS was developed to consider the capacities of individual storage reservoirs and the filling of those storage reservoirs over time as more and more $\mathrm{CO}_{2}$ is injected. In general, the source for which the net levelized CCS costs are lowest gets first access to a given reservoir, followed by the next lowest-cost source, and so on. However, the total estimated storage capacity of each reservoir constrains the amount of $\mathrm{CO}_{2}$ that can be injected into a given unit, and a storage commitment constraint requires that the selected reservoir must be capable of accepting at least a specified number of years worth of the source's $\mathrm{CO}_{2}$ (to justify investment in CCS infrastructure). If such constraints are not met, then the source must seek out and compete for its next best (least-cost) storage option. The application of the $\mathrm{CO}_{2}$-GIS allows for source and reservoir data to be integrated within a geospatial framework, enabling the examination of not only the technical characteristics of $\mathrm{CO}_{2}$ production and storage capacity, but also the role that geographical distribution of sources and reservoirs plays in pairing selection, transport requirements, and overall costs. ${ }^{\text {(b) }}$

In addition to the filling constraint imposed by the $\mathrm{CO}_{2}-G I S$, this analysis for the Alberta Basin will use, for the first time anywhere, the capability of the $\mathrm{CO}_{2}$-GIS to model the dynamic nature of available storage capacity within the basin. While it is assumed that the vast storage capacity in the region's deep saline formations is available and can be accessed at any time, the new schedules for the availability of storage capacity offered by the depleted oil and gas pools can now be modeled. Additionally, given the questions regarding the technical viability of storing $\mathrm{CO}_{2}$ within deep coal seams, a proxy schedule of availability for coal-seam capacity can also been implemented to limit the storage capacity that might be available in coals at each point in time. ${ }^{(\mathrm{c})}$ Therefore, by applying the capabilities of the $\mathrm{CO}_{2}$-GIS along with developed schedules of storage resource availability, we are able to better model CCS deployment and demand for various reservoir storage capacities across the region. This enables the modeling of the demand and competition for the storage capacity as well as the net costs for transport and storage of each plant's $\mathrm{CO}_{2}$.

By considering this important element of timing of resource availability along with the existing modeling of competition for the finite capacity that is available at each point in time, the methodology allows each $\mathrm{CO}_{2}$ source to compete for the lowest net-cost storage capacity within 100 miles that has become

(a) Net costs of $\mathrm{CO}_{2}$ storage include any revenue associated with incremental hydrocarbon recovery (e.g., $\mathrm{CO}_{2}$ EOR or $\mathrm{CO}_{2}$-ECBM), where applicable. Previously documented Reference Case assumptions are applied, although assumed long-term oil and gas prices were updated to $\$ 30.31 / \mathrm{bbl}$ and $\$ 4.79 / \mathrm{mcf}$ (based on EIA 2025 reference prices, DOE/EIA 2005).

(b) For more information on the Battelle $\mathrm{CO}_{2}$-GIS and its modeling capabilities, see IEA GHG (2005).

(c) A linearly increasing schedule of availability was approximated for the coal-seam storage options to be more representative of likely coal-seam availability and utilization (assuming that coal-seam $\mathrm{CO}_{2}$ storage and the necessary infrastructure-wells, compressors and $\mathrm{CO}_{2}$-delivery and $\mathrm{CBM}$ gathering pipelines — currently nonexistent, will be progressively built over time) and to allow more focus on the impact of oil and gas depletion schedules. 
available for use before the start of each decade and that has not already been reserved for use by another source. The result is a more realistic set of cost curves for $\mathrm{CO}_{2}$ transport and storage spanning a number of decades during which an increasing supply of capacity in oil and gas pools is expected to become available.

\section{2 $\mathrm{CO}_{2}$ Storage Cost Curves}

A resulting output capability of the $\mathrm{CO}_{2}$-GIS is the generation of supply or cost curves for $\mathrm{CO}_{2}$ storage in the modeled region. This is created as a result of the cost-optimizing source-reservoir matching analysis, by plotting the annual $\mathrm{CO}_{2}$ stored from a given source into its selected lowest-cost available storage reservoir along with the total net CCS cost in dollars per ton. The resulting curve indicates the volume of storage capacity that may be accessed within the region at a certain price and at that point in time.

Analyses that do not incorporate the estimated schedule of availability for such storage reservoirs will overestimate the availability of this potentially lower cost storage capacity. If it is assumed that all of the estimated capacity in depleted oil and gas fields is available for $\mathrm{CO}_{2}$ injection now, this will also often result in an underestimation of the costs of applying $\mathrm{CCS}$ within a region. Because $\mathrm{CO}_{2}$ storage in depleted oil and gas fields (and perhaps coal seams, if proven technically viable) often incurs a lower net storage cost than other storage options, neglecting the timing of availability can exaggerate the size of these low-cost storage opportunities. An example of the $\mathrm{CO}_{2}$-storage-capacity supply curve for the Alberta Basin, created for the first 10-year analysis period and neglecting the timing of availability, is shown in Figure 4.2. In comparison, Figure 4.3 is a resulting supply curve for the same period in which the availability of depleted oil and gas pools, as well as coal seams, has been incorporated. As is clearly evident, there is significantly less low-cost (and particularly negative net cost) $\mathrm{CO}_{2}$ storage capacity available when actual timing of resource availability is accounted for. 


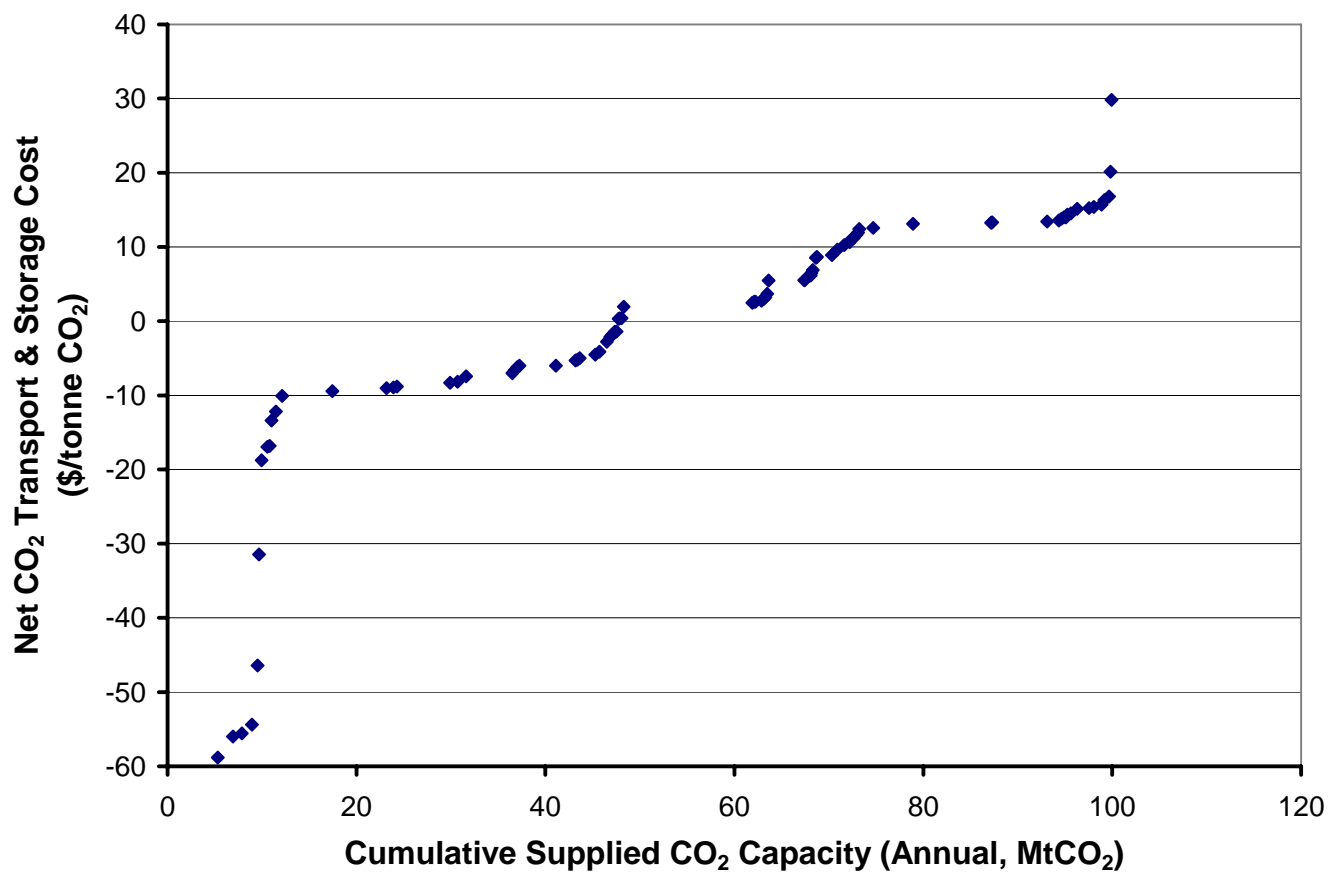

Figure 4.2. Alberta Basin $\mathrm{CO}_{2}$ Transport and Storage "Static" Cost Curve for First 10 Years-Ignoring Timing of Storage Resource Availability

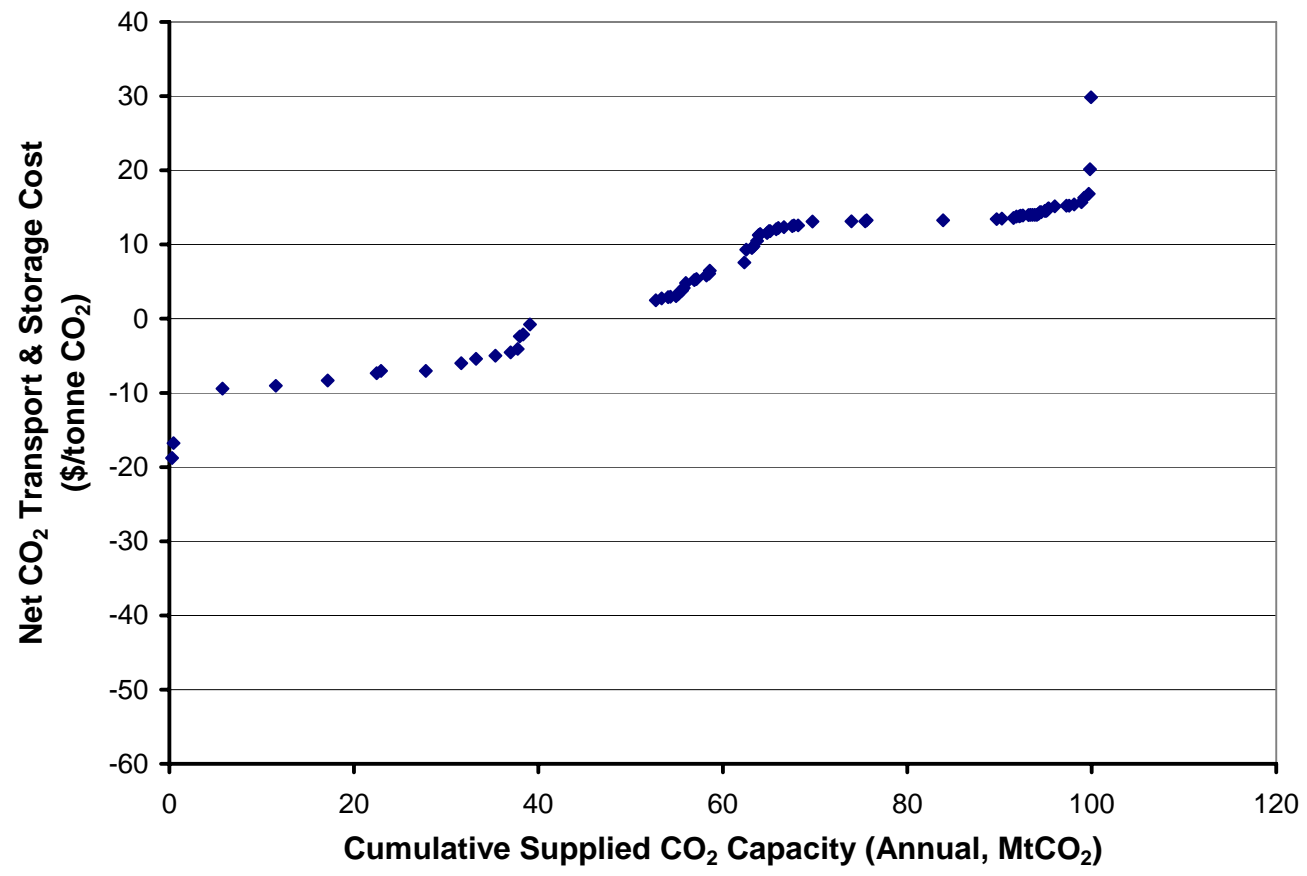

Figure 4.3. Alberta Basin $\mathrm{CO}_{2}$ Transport and Storage "Static" Cost Curve for First 10 YearsConsidering Timing of Storage Resource Availability 


\subsection{Iso-Cost or "Dynamic" Cost Curves}

The "static" supply curves shown above (representing the supply and price of $\mathrm{CO}_{2}$ storage capacity over a single time frame) have limited value when examining the impact of timing of reservoir availability over longer time periods. The cost curve for the initial analysis period alone does not reflect the dynamic nature of the market as additional storage capacity becomes available for use (nor as available capacity becomes consumed). Therefore, a more useful mechanism for examining the longer term supply of storage capacity, accounting also for interim filling, are curves that incorporate the results from a successive series of these static cost curves.

To accomplish this, the schedule of storage capacity availability for the oil and gas pools of the Alberta Basin (as shown in Figure 3.4) was aggregated from yearly additions of storage capacity into the amount of storage capacity that would become available within each decade. The results of the aggregation are shown in Figure 4.4, again colored by pool type. For an analysis that considers CCS deployment beginning in 2010, we see that approximately $771 \mathrm{MtCO}_{2}$ of storage capacity is expected to be available in very large depleted hydrocarbon reservoirs by that time, mostly in non-associated gas and associated oil and gas pools. Over the next 10 years, another $2,133 \mathrm{MtCO}_{2}$ of storage capacity in very large depleted oil and gas pools will become available. Subsequent additions of storage capacity in these very large pools then decline significantly out until the last pools are expected to be depleted post-2060.

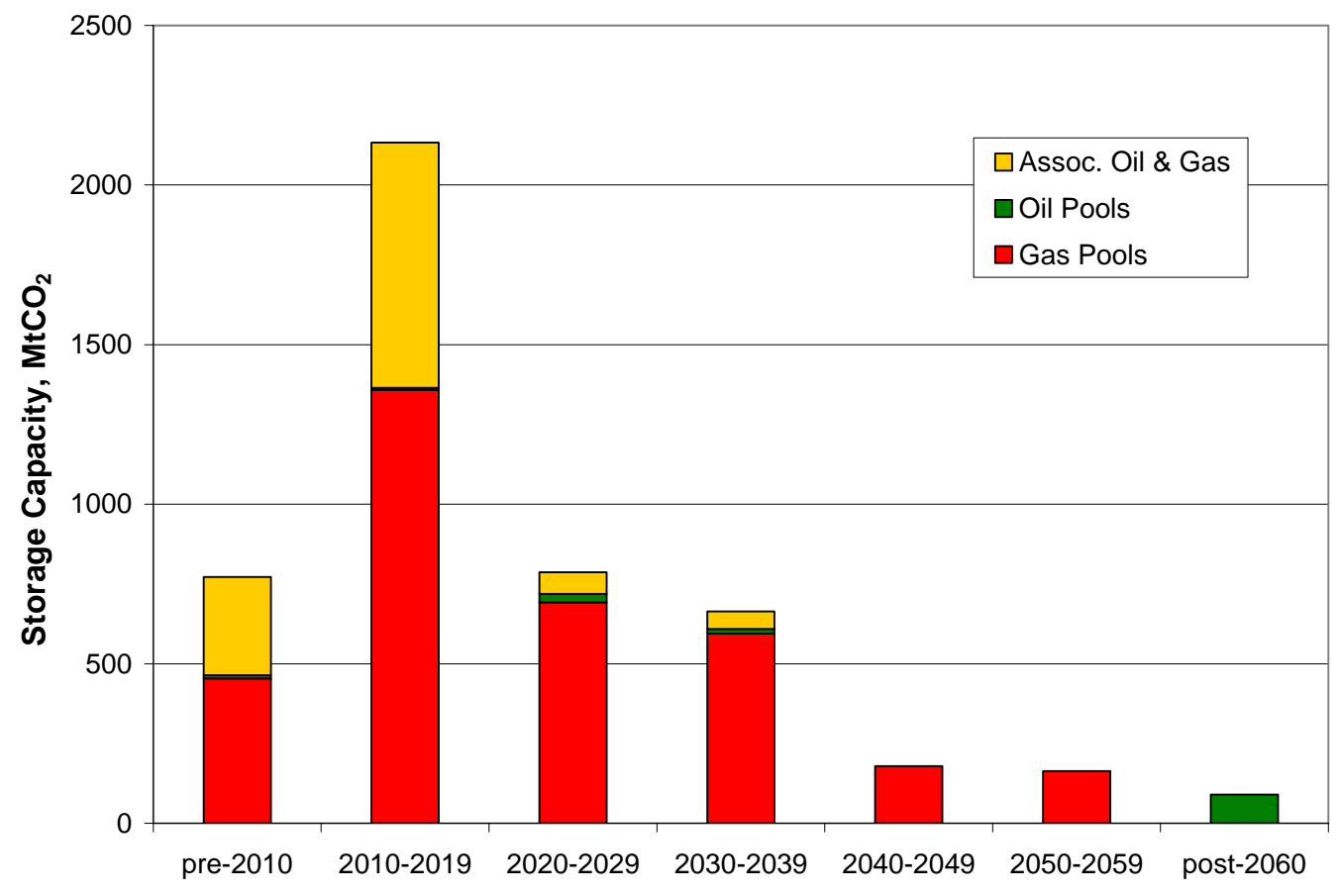

Figure 4.4. Timing of $\mathrm{CO}_{2}$ Storage Capacity Availability Grouped by Decade for the Largest 227 Oil and Gas Reservoirs in the Alberta Basin, Western Canada $\left(\mathrm{MtCO}_{2}\right.$ of new capacity within each time period) 
When this storage resource availability schedule is incorporated within the modeling framework, along with the linearly increasing supply of storage capacity in the deep coal seams, it can have a significant impact on the resulting cost-curve snapshots over time. The "dynamic" or iso-cost curves that result from including these schedules are thereby able to communicate trends in CCS deployment costs and storage reservoir selection. Figure 4.5 shows a preliminary dynamic cost curve for the Alberta Basin, resulting from initial analyses of the data. It charts, by decade, the total annual $\mathrm{CO}_{2}$ storage capacity potentially demanded by the region's large $\mathrm{CO}_{2}$ point sources under a sweeping $\mathrm{CO}_{2}$ storage deployment scenario by net transport and storage costs estimated for each unique pair of $\mathrm{CO}_{2}$ source and its selected storage reservoir. To aid interpretation, the results are presented by grouping the prices into three distinct categories, with each line showing the magnitude of storage capacity utilized at each price level. Due to variations in the characteristics of individual storage formations, as well as to the impact of varying transport costs, these cost bins do not cleanly segregate all of the different storage-reservoir classes; however, they provide good indicators of the predominant storage-reservoir type within each category as follows:

- negative costs $\left(\mathrm{p}<\$ 0 / \mathrm{tCO}_{2}\right)$ consist exclusively of depleted oil reservoirs suitable for $\mathrm{CO}_{2}$-EOR and coal seams with $\mathrm{CO}_{2}$-ECBM potential

- the middle range ( $\mathrm{p}=\$ 0$ to $\$ 10 / \mathrm{tCO}_{2}$ ) includes a mix of mostly oil, gas, and coal storage

- the high-cost group $\left(\mathrm{p}>\$ 10 / \mathrm{tCO}_{2}\right)$ is predominantly represented by deep saline formations.

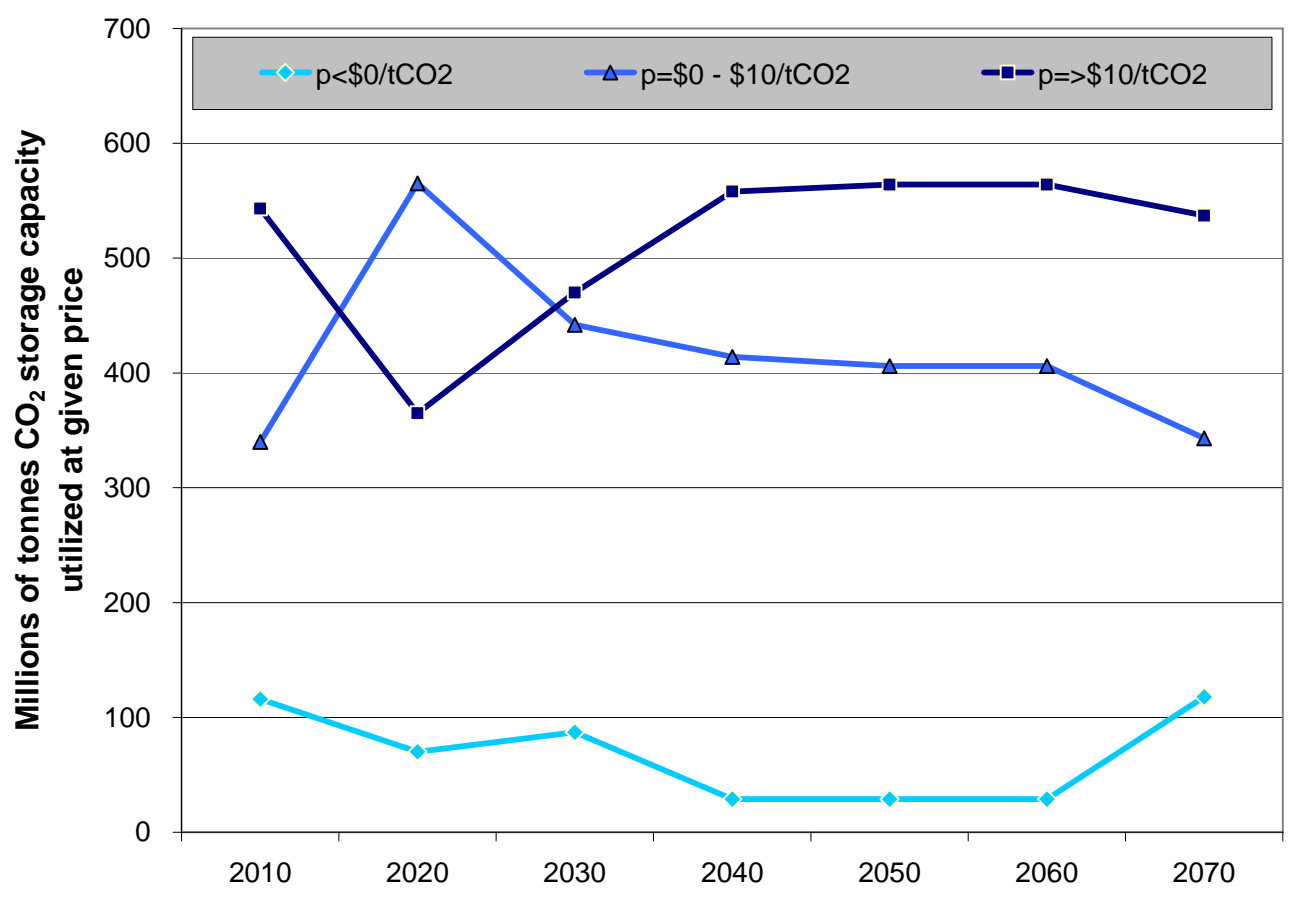

Figure 4.5. Dynamic (iso-cost) $\mathrm{CO}_{2}$ Transport and Storage Cost Curves for the Alberta Basin, Canada, for each Decade Through 2070 


\subsubsection{Initial Results}

Such resulting "dynamic" cost curves are able to more clearly illustrate the likely mix of available storage resource and better represent the ability of the large $\mathrm{CO}_{2}$ point sources to access the region's many different classes of $\mathrm{CO}_{2}$ storage reservoirs over time. Incorporating the of timing of storage-capacity availability within this methodology results in a marked impact on the resulting cost curves and the ability of the region's sources to access this capacity (which shows up within several of the different cost categories). Over this time frame, a reduction of initial access to the oil- and gas-pool capacity is apparent, along with a more uniform distribution of availability in later years. One consequence is that demand for storage within the vast deep saline formations that underlie these pools (predominantly occurring within the $\$ 10$ to $\$ 15 /$ tonne price bin) is simultaneously shifted into earlier use and becomes better balanced through time, at least while available capacity remains within the basin's oil and gas pools.

The impact that oil- and gas-pool timing of $\mathrm{CO}_{2}$ storage availability has on net transport and storage costs can clearly be seen by comparing Figure 4.3 with Figure 4.4. The most obvious impact is visible in the large spike in capacity that is utilized in the middle ( $\$ 0$ to $\left.\$ 10 / \mathrm{tCO}_{2}\right)$ cost range, which corresponds to the large amount of $\mathrm{CO}_{2}$ storage capacity in oil and gas reservoirs that is expected to become available within the basin by 2020, effectively offsetting storage in the higher cost deep saline formations. Other impacts are apparent, although more subtle, due to the smaller magnitudes of depleted oil and gas capacity becoming available, and the curves clearly show that the utilization of storage capacity in the Alberta Basin responds to the availability of the lower cost storage reservoirs.

When comparing this dynamic cost curve to our previous cost curve analyses for the region (as represented by the cost curve in Figure 4.2), one distinct consequence resulting from the incorporation of the expected timing of availability is that demand for storage within the region's vast deep saline formations is pressed into service earlier and in larger quantity. Even during periods when significant storage capacity is available within depleted oil and gas reservoirs, deep saline formations are utilized by a significant fraction of the $\mathrm{CO}_{2}$ seeking storage capacity. Because of their small relative capacities, by building infrastructure to simultaneously or progressively access multiple proximate oil and gas pools, the fraction of total $\mathrm{CO}_{2}$ stored in the basin's oil and gas pools would likely increase, yet deep saline formations would still remain a key option for large-scale deployment of $\mathrm{CO}_{2}$ storage in the basin. Another important finding relates to the value that the success of ECBM technology has on $\mathrm{CO}_{2}$ storage economics in the region. The availability of $\mathrm{CO}_{2}$ storage capacity in coal seams offers a potentially significant additional low-cost storage option that, if not viable, would place further demand on the depleted gas pools and ultimately on the region's deep saline formations. 


\subsection{Conclusions}

The Alberta Basin provides a very large capacity for $\mathrm{CO}_{2}$ storage in oil and gas reservoirs, deep saline formations and, potentially, in deep, unmineable coal beds. Although it is generally accepted that deep saline formations provide globally the largest $\mathrm{CO}_{2}$-storage capacity, the capacity of oil and gas reservoirs is locally significant in regions that are major energy producers such as the Alberta Basin. This storage capacity is most likely to be sought first for a number of reasons, among them the existence of a large infrastructure (pipelines and wells) already in place, good knowledge of reservoir characteristics, and the potential for producing additional oil and possibly gas, which would partially offset the cost of $\mathrm{CO}_{2}$ capture and storage.

The purpose of this report was to describe the motivation, data, and methodology for assessing the impact that the timing of availability may have on CCS deployment decisions and what it can tell us about the value of various types of storage reservoirs. The 2004 reserves databases of Alberta and British Columbia were used to calculate updated estimates of $\mathrm{CO}_{2}$ storage capacity based on the methodology described in Chapter 2. There were a total of 37,713 oil and gas reservoirs in the Alberta Basin that were identified as being suitable for $\mathrm{CO}_{2}$ storage and having all the critical data needed for capacity calculations. The combined effective $\mathrm{CO}_{2}$-storage capacity in the 8,475 oil pools and 29,238 gas pools in the basin that are not commingled (of which 1,602 are oil pools with an associated gas pool) is $\sim 10 \mathrm{GtCO}_{2}$, which is more than 40 times the total of current annual $\mathrm{CO}_{2}$ emissions in the basin and $\sim 65$ times the amount of $\mathrm{CO}_{2}$ emitted annually by the large final emitters in the Alberta Basin.

The individual $\mathrm{CO}_{2}$-storage capacity of the great majority of the hydrocarbon pools in the Alberta Basin that are not commingled is very small ( $270 \mathrm{ktCO}_{2}$ on average). Only 227 hydrocarbon pools have an individual capacity greater than $5 \mathrm{MtCO}_{2}$ each (for comparison, a coal-fired power plant or an oil-sands plant emits 5 to $8 \mathrm{MtCO}_{2}$ /year). These pools have a cumulative $\mathrm{CO}_{2}$-storage capacity of $\sim 4.8 \mathrm{GtCO}_{2}$ (47\% of the total), of which $4.42 \mathrm{GtCO}_{2}$ capacity is in gas pools. Some of these pools are as shallow as $380 \mathrm{~m}$ and as deep as 4,875 m; however, given their very large capacity, these shallow or very deep pools should not be excluded from further consideration. Using production-decline analysis, the estimated depletion date was calculated for each pool, providing for the first time a regional indication of the timing of availability for this $\mathrm{CO}_{2}$ storage resource. Twenty-eight pools with a total storage capacity of $\sim 513 \mathrm{MtCO}_{2}$ are immediately available for $\mathrm{CO}_{2}$ storage. The last pool will be available for $\mathrm{CO}_{2}$ storage in 2062 .

To understand the overall impact of this potential $\mathrm{CO}_{2}$ storage resource and its timing of availability on the regional deployment of CCS technologies to combat climate change, source-reservoir matching and economic modelling within a GIS framework is needed. A methodology was developed to assess the regional adoption of CCS with identification of cost-optimized storage options, considering transport and net storage costs, and reservoir filling and commitment constraints. Integrating the timing of depleted oiland gas-pool storage capacity, along with coal storage capacity, results in significant improvement in the ability to model realistic access to lower cost storage options and therefore the overall costs of CCS deployment. The development of dynamic cost curves allows these impacts to be viewed more readily over longer time frames as some $\mathrm{CO}_{2}$ storage capacity is filled and other comes online.

When comparing this dynamic cost curve to our previous cost curve analyses (e.g., IEA GHG 2005), one distinct consequence resulting from incorporating the expected timing of availability is that demand for 
storage within the region's vast deep saline formations is pressed into service earlier and in larger quantity. Even during periods when significant storage capacity is available within depleted oil and gas reservoirs, deep saline formations are utilized by a significant fraction of $\mathrm{CO}_{2}$ seeking storage capacity. Because of their small relative capacities, by building infrastructure to simultaneously or progressively access multiple proximate oil and gas pools, the fraction of total $\mathrm{CO}_{2}$ stored in the basin's oil and gas pools would likely increase, yet deep saline formations would still remain a key option for large-scale deployment of $\mathrm{CO}_{2}$ storage in the basin. Another important initial finding relates to the value that the success of ECBM technology has on $\mathrm{CO}_{2}$ storage economics in the region. The availability of $\mathrm{CO}_{2}$ storage capacity in coal seams offers a potentially significant additional low-cost storage option that, if not viable, would place further demand on the depleted gas pools and ultimately on the region's deep saline formations.

Sixty percent of the Alberta Basin's estimated large $\mathrm{CO}_{2}$ storage capacity in depleted oil and gas pools will be available by 2020 , thus indicating that there is a potential narrow window with which to start making informed decisions about how to best access this storage capacity. The lower cost capacity provided by depleted oil and gas reservoirs is important and likely to be sought first once it becomes available, yet higher cost storage options should not be ignored; storage in deep saline formations will need to provide a large portion of the utilized storage capacity earlier than previously believed. Overall, the results of the analysis demonstrate that $\mathrm{CO}_{2}$ capacity estimates by themselves can be misleading when they do not account for timing of availability, and they serve to remind us that the magnitude of storage capacity is not as important as whether sufficient economic capacity is available in the right places and at the right times. The early and continued role that $\mathrm{CO}_{2}$ storage in deep saline formations must play, even in regions rich in hydrocarbon resources such as the Alberta Basin in Canada and similar areas elsewhere, is an important result of this research.

Although it is generally accepted that deep saline aquifers provide globally the largest $\mathrm{CO}_{2}$-storage capacity, the availability of lower cost oil and gas reservoirs is significant in regions that are major energy producers, such as the Alberta Basin in Canada. Where available to meet the demand of large $\mathrm{CO}_{2}$ sources, this storage capacity provides an important resource and is likely to be among the first utilized, for a number of reasons, including the existence of usable in-place infrastructure, good and up-to-date knowledge of reservoir characteristics, and the potential for producing additional hydrocarbons, which could partially offset the cost of $\mathrm{CO}_{2}$ capture and storage. However, the timing of availability for candidate $\mathrm{CO}_{2}$ storage reservoirs is a key element of regional $\mathrm{CO}_{2}$ capture and storage assessments, and one that has until now been neglected. Accounting for estimated depletion dates of oil and gas pools within a regional assessment enables a more realistic examination of net storage capacity and costs for those reservoirs that are accessible to the region's large $\mathrm{CO}_{2}$ emitters. The dynamic cost curves that result from this work present a more accurate picture of storage-capacity demand and provide important input to regional infrastructure development and reservoir access strategies that should be considered when planning $\mathrm{CO}_{2}$ capture and storage activities. 


\subsection{References}

Bachu S. 2003. "Screening and ranking of sedimentary basins for sequestration of $\mathrm{CO}_{2}$ in geological media." Environmental Geology 44(3):277-289.

Bachu S, and AT Lytviak. 2005. Carbon Dioxide Storage Capacity in Uneconomic Coal Beds in Alberta: Potential and Site Identification. Report to Plains $\mathrm{CO}_{2}$ Reduction (PCOR) Partnership, Alberta Geological Survey, Edmonton, AB.

Bachu S, and JC Shaw. 2003. "Evaluation of the $\mathrm{CO}_{2}$ sequestration capacity in Alberta's oil and gas reservoirs at depletion and the effect of underlying aquifers." Journal of Canadian Petroleum Technology 42(9):51-61.

Bachu S, and JC Shaw. 2005. " $\mathrm{CO}_{2}$ storage in oil and gas reservoirs in western Canada: Effect of aquifers, potential for $\mathrm{CO}_{2}$-flood enhanced oil recovery and practical capacity." In: Proceedings of the 7th International Conference on Greenhouse Gas Control Technologies (GHGT-7), Volume 1: PeerReviewed Papers and Overviews (ES Rubin, DW Keith, and CF Gilboy, eds.), Elsevier, 361-369.

Bachu S, and S Stewart. 2002. "Geological sequestration of anthropogenic carbon dioxide in the Western Canada Sedimentary basin: Suitability analysis." Journal of Canadian Petroleum Technology 41(2):32-40.

Bachu S, JC Shaw, and RM Pearson. 2004. "Estimation of oil recovery and $\mathrm{CO}_{2}$ storage capacity in $\mathrm{CO}_{2}$-EOR incorporating the effect of underlying aquifers." SPE Paper 89340, presented at the Fourteenth SPE/DOE Improved Oil Recovery Symposium, Tulsa, OK, April 17-21, 2004.

Dahowski RT, and JJ Dooley. 2004. "Carbon management strategies for U.S. electricity generation capacity: a vintage-based approach.” Energy 29(9-10):1589-1598.

Dooley JJ, RT Dahowski, CL Davidson, MA Wise, N Gupta, SH Kim, EL Malone. 2006. Carbon Dioxide Capture and Geologic Storage: A Key Component of a Global Energy Technology Strategy to Address Climate Change. PNWD-3602, Joint Global Change Research Institute, Battelle-Pacific Northwest Division, College Park, MD.

Doughty C, and K Pruess. 2004. "Modeling supercritical carbon dioxide injection in heterogeneous porous media." Vadose Zone Journal 3(3):837-847.

Hadlow RE. 1992. "Update of industry experience with $\mathrm{CO}_{2}$ injection." SPE Paper 24928, presented at the Sixty Seventh SPE Annual Technical Conference, October 4-7, 1992, Washington, D.C.

Hitchon B, WD Gunter, T Gentzis, and RT Bailey. 1999. "Sedimentary basins and greenhouse gases: a serendipitous association." Energy Conversion and Management 40(8):825-843.

Holt T, JI Jensen, and E Lindeberg. 1995. "Underground storage of $\mathrm{CO}_{2}$ in aquifers and oil reservoirs." Energy Conversion and Management 36:535-538.

International Energy Agency Greenhouse Gas R\&D Programme (IEA GHG). 2005. Building the Cost Curves for $\mathrm{CO}_{2}$ Storage: North America. Report 2005/3, Cheltenham, U.K. 
Intergovernmental Panel on Climate Change (IPCC). 2005. IPCC Special Report on Carbon Dioxide Capture and Storage (B. Metz, O. Davidson, H.C. de Coninck, M. Loos and L.A. Mayer, eds.), Cambridge University Press, Cambridge, U.K., and New York, NY, U.S.A.

Kovscek AR. 2002. "Screening criteria for $\mathrm{CO}_{2}$ storage in oil reservoirs." Petroleum Science and Technology 20(7-8):841-866.

Lasater JA. 1958. "Bubble point pressure correlation.” Transactions AIME 213:379-381.

Mungan N. 1981. "Carbon dioxide flooding - fundamentals." Journal of Canadian Petroleum Technology 20(1):87-92.

Shaw J, and S Bachu. 2002. "Screening, evaluation, and ranking of oil reservoirs suitable for $\mathrm{CO}_{2}$-flood EOR and carbon dioxide sequestration." Journal of Canadian Petroleum Technology 41(9):51-61.

Span P, and W Wagner. 1996. "A new equation of state for carbon dioxide covering the fluid region from the triple-point temperature to $1100 \mathrm{~K}$ at pressures up to $800 \mathrm{MPa}$." Journal of Chemical Reference Data 25(6):1509-1596.

Stevens SH, VA Kuuskra, and J Gale. 2001. "Sequestration of $\mathrm{CO}_{2}$ in depleted oil \& gas fields: global capacity, costs and barriers." In: Proceedings of the 5th International Conference on Greenhouse Gas Control Technologies (GHGT- 5) (DJ Williams, RA Durie, P McMullan, CAJ Paulson, and AY Smith, eds.), CSIRO Publishing, Collingwood, VIC, Australia, 278-283.

Taber JJ, FD Martin, and RS Seright. 1997. "EOR screening criteria revisited - part 1: introduction to screening criteria and enhanced recovery field projects." SPE Reservoir Engineering 12(3):189-198.

True W. 2002. "Special Report Pipeline Economics: Fed data show solid 2001 for U.S. pipeline companies, more gas capacity planned." Oil \& Gas Journal 100(38):52-69.

Winter EM, and PD Bergman. 1993. "Availability of depleted oil and gas reservoirs for disposal of carbon dioxide in the United States." Energy Conversion and Management 34(9-11):1177-1187.

U.S. Department of Energy, Energy Information Administration (DOE/EIA). 2005. Assumptions for the Annual Energy Outlook 2005. DOE/EIA-0554(2005), Washington D.C. 
PNNL-16137

\section{Distribution}

No. of

Copies

OFFSITE

5 Alberta Energy and Utilities Board

Alberta Geological Survey

Stefan Bachu

Geoscience Advisor

4999 - 98th Avenue

Edmonton, Alberta T6B 2X3

Canada

1 Zero Emissions Research and Technology

Center

Montana State University

Lee Spangler

ZERT Center Director

Director of Special Programs

PO Box 172460

Bozeman, MT 59717-2460

Zero Emissions Research and Technology

2 U.S. Department of Energy

National Energy Technology Laboratory

Dawn Deel

Sequestration Project Manager

3610 Collins Ferry Road

PO Box 880

Morgantown, WV 26507

Sean Plasynski

Sequestration Technology Manager

626 Cochrans Mill Road

PO Box 10940

Pittsburgh, PA 15236
No. of

Copies

OFFSITE

2 Battelle Columbus

505 King Ave.

Columbus, OH 43201-2693

Attn: Neeraj Gupta

Mark Kelley

1 Joint Global Change Research Institute

Pacific Northwest National Laboratory

Jim Dooley

Senior Staff Scientist

8400 Baltimore Avenue, Suite 201

MS-JGCRI

College Park, MD 20740

ONSITE

19 Pacific Northwest National Laboratory

J. E. Amonette K8-96

R. T. Dahowski (5) K6-10

C. L. Davidson K6-10

K. K. Humphreys K1-98

K. M. Krupka K6-81

P. F. Martin K6-81

W. J. Martin K6-81

B. P. McGrail K6-81

E. M. Pierce K3-62

B. F. Saffell, Jr. K1-98

H. T. Schaef K6-81

S. A. Shankle K1-85

F. A. Spane K6-96

C. Sullivan K6-81

M. D. White K9-33

Distr. 1 